\title{
Arene-Metal-Ion Contact: A Multicolor and Ratiometric Fluorescence Sensing Platform for Metal Ions
}

\author{
Anna Kanegae \\ Kyushu University

\section{Yusuke Takata} \\ Kyushu University \\ Ippei Takashima \\ Kyushu University \\ Shohei Uchinomiya \\ Kyushu University

\section{Ryosuke Kawagoe} \\ Kyushu University \\ Kazuteru Usui \\ Kyushu University \\ Jirarut Wongkongkatep \\ Mahidol University \\ Manabu Sugimoto \\ Kumamoto University
}

Akio Ojida ( $\nabla$ ojida@phar.kyushu-u.ac.jp )

Kyushu University https://orcid.org/0000-0002-9440-8167

Article

Keywords: metal ions, fluorescence sensing, ratiometric detection

Posted Date: August 14th, 2020

DOl: https://doi.org/10.21203/rs.3.rs-55176/v1

License: (c) (i) This work is licensed under a Creative Commons Attribution 4.0 International License. Read Full License

Version of Record: A version of this preprint was published at Communications Chemistry on July 6th, 2021. See the published version at https://doi.org/10.1038/s42004-021-00541-y. 


Metal Ions

Anna Kanegae, ${ }^{1,4}$ Yusuke Takata, ${ }^{1,4}$ Ippei Takashima, ${ }^{1}$ Shohei Uchinomiya, ${ }^{1}$ Ryosuke Kawagoe, ${ }^{1}$

email: ojida@phar.kyushu-u.ac.jp

ABSTRACT: Despite continuous active development of fluorescent probes for metal-ions, their molecular design for ratiometric detection is limited owing to a narrow choice of available sensing mechanisms. We present herein a dual-emission sensing platform for metal ions based on contact interaction between a coordinated metal ion and the aromatic ring of a fluorophore (i.e., arenemetal-ion contact). Our structure-based ligand design provided a new probe possessing 1,9-bis(2'pyridyl)-2,5,8-triazanonane as the metal ion binding unit, which was flexibly concatenated to a tricyclic fluorophore. This molecular architecture allowed us to fluorescently sense various metal ions such as $\mathrm{Zn}(\mathrm{II}), \mathrm{Cu}(\mathrm{II}), \mathrm{Cd}(\mathrm{II}), \mathrm{Ag}(\mathrm{I})$, and $\mathrm{Hg}(\mathrm{II})$ with the red-shifted emissions. This probe design was applicable to a series of tricyclic fluorophores, enabling ratiometric detection of the metal ions across the blue to near-infrared wavelength region. X-ray crystallography and theoretical computational calculation indicated that the coordinated metal ion has van der Waals contact with the fluorophore, which perturbs its electronic structure and ring conformation to induce the emission red-shift. A set of the arene-metal-ion contact probes was used for the differential sensing of eight metal ions in a one-pot single titration via principal component analysis. Furthermore, the probe with a xanthene fluorophore was applicable to the ratio imaging of metal ions under livecell conditions. 
Fluorescent molecular probes are essential research tools in many fields as they can provide sensitive and selective detection of chemical species in real time. Among their sensing targets, metal ions have attracted special interest because of their significant biological effects. For harmful, non-essential heavy metal ions (mercury, cadmium, lead, etc.), fluorescent probes serve as tools to understand their biological behaviors in animals and plants ${ }^{1}$, which occur as a result of unwanted uptake from the environment. Indeed, the detection of these harmful metal ions in organisms has been the subject of biological research for the last thirty years, and extensive studies are still being done to elucidate their multiple biological actions associated with their toxic effects. ${ }^{2,3}$ Meanwhile, monitoring toxic metal ion contamination in the environment is also an important task for preserving global health. ${ }^{4}$ For biologically relevant metal ions (calcium, zinc, copper, iron, etc.), detection of their localization and stimuli-dependent concentration change in live cell and tissue contexts facilitates understanding of their physiological and pathological roles. ${ }^{5-7}$

Fluorescent probes for metal ions are typically designed by connecting a coordination binding (ligand) unit to a luminescent sensing unit. ${ }^{8}$ Design of the coordination ligand with high selectivity and tuned binding affinity for a target metal ion has been well developed as a result of the accumulated knowledge of coordination chemistry and supramolecular chemistry. Meanwhile, exploitation of new mechanism for metal ion sensing, which can effectively transduce the metal ion binding event to a fluorescence signal change, is still a challenging task. ${ }^{9-10}$ The conventional and most widely used sensing mechanism for metal ions is PET (photoinduced electron transfer). ${ }^{11}$ AIE (aggregation-induced emission) ${ }^{12}$ and chemical reaction-based mechanisms (i.e., activitybased sensing $)^{9,10,13}$ have also been exploited for metal ion sensing in recent years. In addition to these off-on type fluorescence sensing mechanisms, PCT (photoinduced charge transfer) ${ }^{14}$ and FRET (fluorescence energy transfer) ${ }^{15}$ have been used for the dual-emission ratiometric sensing of metal ions. However, they have rather limited utility as the former can only work with a limited class of fluorophores and the latter demands a complex probe structure owing to the necessity of using two fluorophores. Given these limitations that restrict broader application of fluorescent probes for quantitative and accurate ratiometric analysis, ${ }^{16}$ there still exists a need for new molecular system for the ratiometric detection of metal ions. We envisioned that such new sensing system should (1) work flexibly with different types of fluorophores, (2) function effectively within simple molecular architectures, and (3) be broadly applicable to various metal ion sensing. These desirable functions would facilitate not only quantitatively detect various metal ions at a desired wavelength but also identification of a specific metal ion with high accuracy. In this article, we report the new ratiometric fluorescent probes for metal ions based on contact interaction between the coordinated metal ion and the aromatic ring of the fluorophore (i.e., arene-metal-ion contact). 
Introduction of a semicyclic ligand to a tricyclic fluorophore provided a designer probe, which forms an arene-metal-ion van der Waals contact (AM-contact) upon coordination to cause an emission red-shift. We found that this probe design is broadly applicable to various tricyclic fluorophores, the emissions of which cover a broad wavelength range of over $400 \mathrm{~nm}$. A set of the AMcontact probes provided a multicolor fluorescence sensing system, which enabled us to distinguish several metal ions by one-pot single titration and principal component analysis (PCA). Probe with the xanthene fluorophore was also applicable to the ratiometric detection of various metal ions under live-cell conditions. These analytical applications demonstrate the broad utility of AMcontact sensing in fluorescence metal ion analyses.

\section{Design of fluorescent probes}

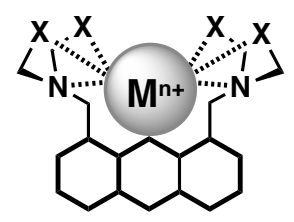

Type I

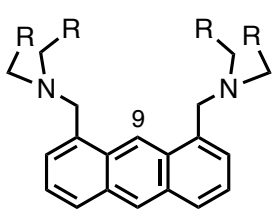

1: $R=2-$ pyridyl

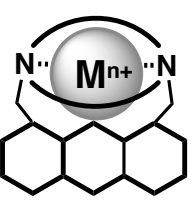

Type II

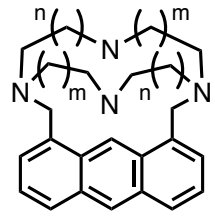

2: $\mathrm{n}=1, \mathrm{~m}=1$

3: $n=1, m=2$

4: $n=2, m=2$

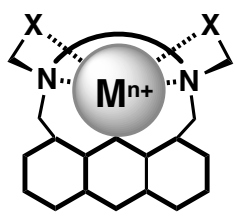

Type III

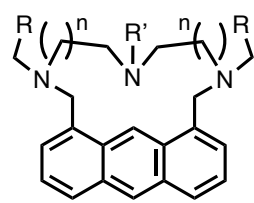

5: $n=1, R=2$-pyridyl, R'=H

6: $\mathrm{n}=2, \mathrm{R}=2$-pyridyl, $\mathrm{R}^{\prime}=\mathrm{H}$

7: $n=1, R, R^{\prime}=2$-pyridyl

Figure 1. General designs (upper) and molecular structures (lower) of tricyclic fluorescent probes for metal ion sensing based on arene-metal-ion contact (AM-contact).

We previously reported that a Type-I probe serves as the ratiometric fluorescent chemosensor for metal ions based on AM-contact sensing (Figure 1). ${ }^{17}$ For example, probe 1, bearing two sets of 2,2'-dipicolylamine (i.e., $\mathrm{R}=2$-pyridyl), exhibited a large emission red-shift upon binding with $\mathrm{Cd}(\mathrm{II})$, which was induced by forming van der Waals contact between the C9 carbon of the fluorophore and the metal ion in a 1:1 binding complex. However, while Type-I probes fluorescently responded to 4d- and 5d-block metal ions such as $\mathrm{Cd}(\mathrm{II}), \mathrm{Ag}(\mathrm{I})$, and $\mathrm{Hg}(\mathrm{II})$, they did not show an emission shift with 3d-block metal ions such as $\mathrm{Zn}(\mathrm{II})$. This limitation was mainly ascribed to the unfavorable formation of 1:2 binding complex with the rather small 3d-block metal ions at the ligand sites, which prohibited the van der Waals contact with the fluorophore. To solve this problem, we designed a Type-II probe (Figure 1) possessing a single tetra-aza cyclic ligand. ${ }^{18,19}$ It was 
expected that the Type-II probe would preferably form close van der Waals contact in a 1:1 metal ion complex. However, Type-II probes 2-4 were not able to fluorescently respond to most of the 3d-block metal ions such as $\mathrm{Cr}(\mathrm{II}), \mathrm{Mn}(\mathrm{II}), \mathrm{Co}(\mathrm{II}), \mathrm{Ni}(\mathrm{II}), \mathrm{Zn}(\mathrm{II}), \mathrm{Ag}(\mathrm{I}), \mathrm{Cd}(\mathrm{II})$, and $\mathrm{Pb}(\mathrm{II})$, with the exception of $\mathrm{Cu}$ (II) (Figure $\mathrm{S} 1$, Table $\mathrm{S} 1$ ). In the case of $\mathrm{Cu}$ (II), the probes decreased their fluorescence intensities without emission shift. We concluded that these unwanted results were primarily a result of the weak metal ion coordination ability of the conformationally constrained aza-cyclic ligands, which are concatenated to an anthracene ring at the 1,8-position. We next designed a Type-III probe, which possessed a conformationally more flexible semicyclic ligand (Figure 1). Probes 5-7, each bearing a different semicyclic ligand, were synthesized according to standard methods, and their fluorescence response toward metal ions was evaluated under aqueous $\mathrm{MeOH}$ conditions (50 mM HEPES ( $\mathrm{pH} 7.4) / \mathrm{MeOH}=1: 1)$.

a

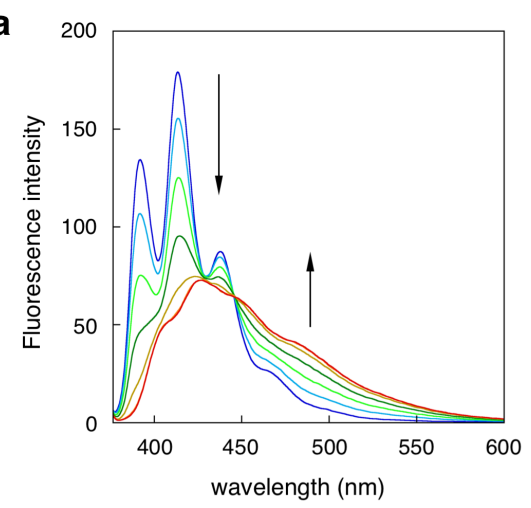

C

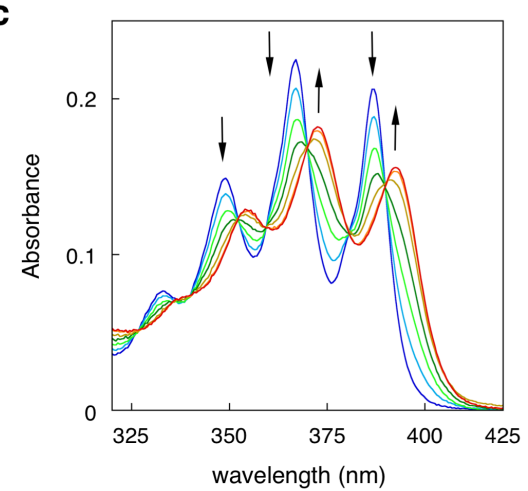

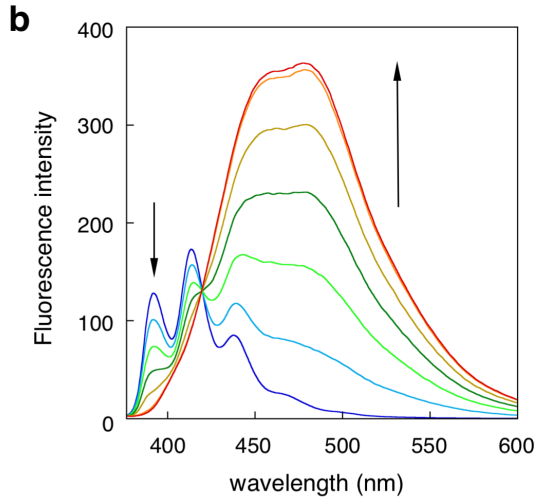

d

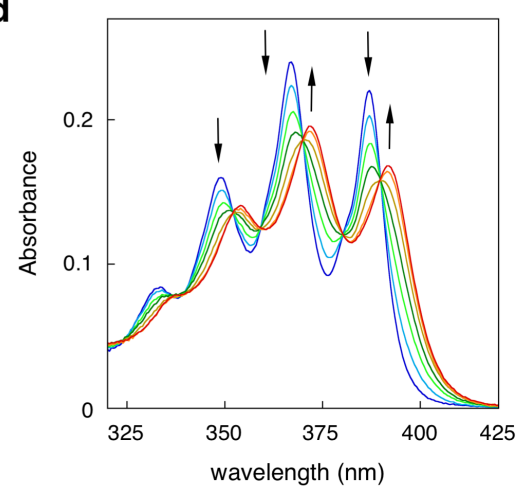

Figure 2. Fluorescence and absorption spectral changes of probe 5 upon addition of $\mathrm{ZnCl}_{2}$ (a and c) or $\mathrm{CdCl}_{2}$ (b and d). Measurement conditions: [5] $=25 \mu \mathrm{M},\left[\mathrm{ZnCl}_{2}\right.$ or $\left.\mathrm{CdCl}_{2}\right]=0-30 \mu \mathrm{M}, 50$ $\mathrm{mM}$ HEPES $(\mathrm{pH} 7.4) / \mathrm{MeOH}=1: 1, \lambda_{\mathrm{ex}}=365 \mathrm{~nm}, 25^{\circ} \mathrm{C}$.

111 To our delight, probe 5 bearing a 1,9-bis(2'-pyridyl)-2,5,8-triazanonane (BPTN) ligand exhibited 112 a significant emission red-shift $(\Delta F=14 \mathrm{~nm})$ upon the addition of $\mathrm{Zn}(\mathrm{II})$ (Figure 2a). The fluores113 cence change of 5 was concomitant with a bathochromic absorption shift $(\Delta \mathrm{Abs}=6 \mathrm{~nm}$ ) (Figure 
2c), suggesting that the $\mathrm{Zn}(\mathrm{II})$ coordination influences the electrophysical property of the anthracene in the ground state. The fluorescence molar ratio plot clearly suggests that 5 forms a 1:1 binding complex with $\mathrm{Zn}$ (II) (Figure S2). The binding affinity of 5 to $\mathrm{Zn}$ (II) was $2.70 \times 10^{6} \mathrm{M}^{-1}$ as evaluated by fluorescence titration (Figure S3, Table S2). Conversely, probes 6 and 7 showed negligible emission shift upon the addition of $\mathrm{Zn}$ (II) (Figure S4). Probe 5 also displayed a large emission red-shift $(\Delta F=65 \mathrm{~nm})$ and a bathochromic absorption shift $(\Delta \mathrm{Abs}=5 \mathrm{~nm})$ (Figure 2b,d) upon complexation with $\mathrm{Cd}(\mathrm{II})\left(K_{a}=9.50 \times 10^{6} \mathrm{M}^{-1}\right)$ (Figure S3, Table S2), while 6 and 7 showed smaller emission shifts ( $\Delta F=6$ and $12.5 \mathrm{~nm}$, respectively) compared with 5 (Figure S4).

\section{Ratiometric sensing with various fluorophores}

We next replaced the anthracene of 5 with other tricyclic fluorophores and evaluated the fluorescence sensing properties of this series of Type-III probes (Figure 3). Probes 8-11 possess the fluorophores coumarin, xanthene, pyronine, and Si-pyronine, respectively. The emission wavelengths of 5 and 8-11 cover a wide range from 380 to $800 \mathrm{~nm}$. In addition to the difference in the emission wavelength, structural analysis of the fluorophores by density functional theory (DFT) suggested that the distance between the two methyl groups at their 1,8-positions (4,6-position in the case of coumarin 8) varies from 4.64 to $5.21 \AA$ (Figure 3). We expected that this structural difference could also affect the sensing and binding properties of the Type-III probes to metal ions. The detailed synthetic procedures and characterizations of the probes are described in the supporting information. The absorbance and fluorescence properties of the probes are summarized in Table 1.
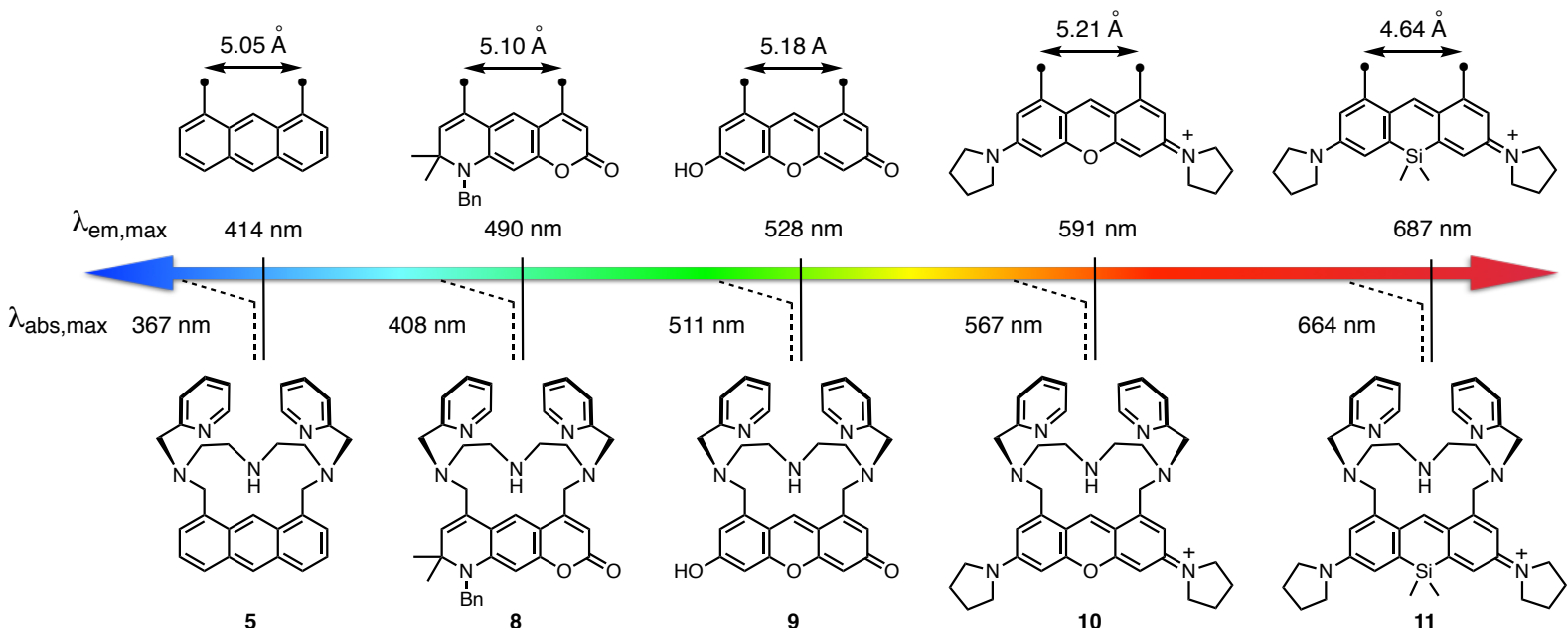

Figure 3. Structures and fluorescence spectroscopic properties of tricyclic fluorophore probes bearing a BPTN ligand. 
Table 1. Summary of optical properties of Type-III probes 5 and $8-11$. $^{\text {a }}$

\begin{tabular}{|c|c|c|c|c|}
\hline & $\lambda_{\text {abs,max }}(\mathrm{nm})$ & $\varepsilon\left(\mathrm{cm}^{-1} \cdot \mathrm{M}^{-1}\right)$ & $\lambda_{\text {em,max }}(\mathrm{nm})$ & $\Phi$ \\
\hline $\mathbf{5}$ & 367 & 8,500 & 414 & 0.03 \\
\hline $\mathbf{8}$ & 408 & 19,500 & 490 & 0.50 \\
\hline $\mathbf{9}$ & 511 & 66,000 & 528 & 0.24 \\
\hline $\mathbf{1 0}$ & 567 & 138,000 & 591 & 0.53 \\
\hline $\mathbf{1 1}$ & 664 & 138,500 & 687 & 0.30 \\
\hline
\end{tabular}

${ }^{\mathrm{a}} \mathrm{All}$ measurements were conducted in $50 \mathrm{mM}$ HEPES $(\mathrm{pH} 7.4) / \mathrm{MeOH}=1: 1,25^{\circ} \mathrm{C}$.

a

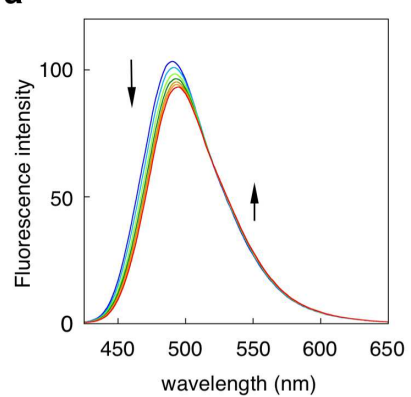

e

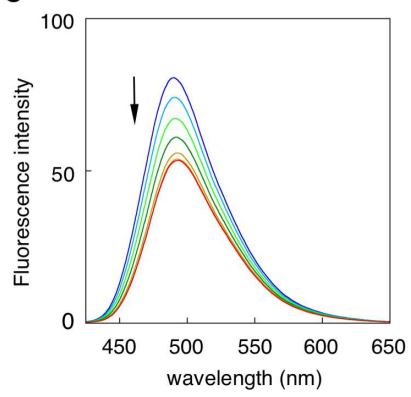

b
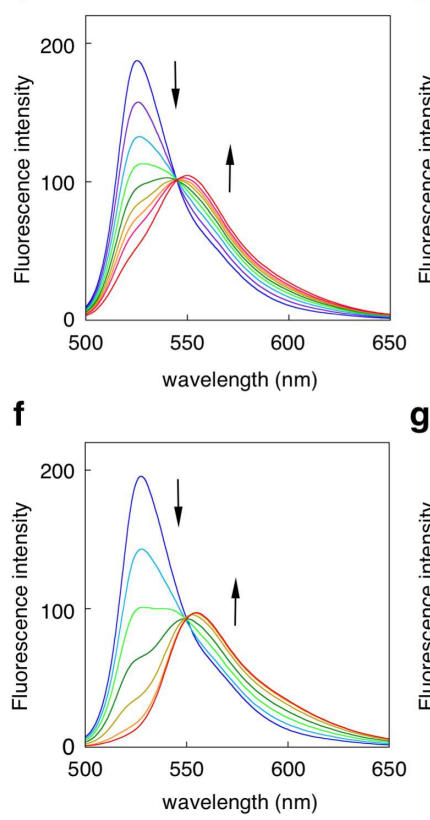

c
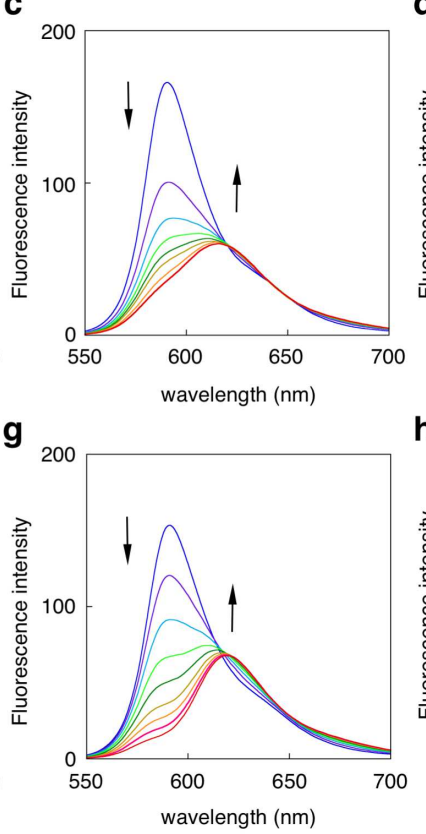

d

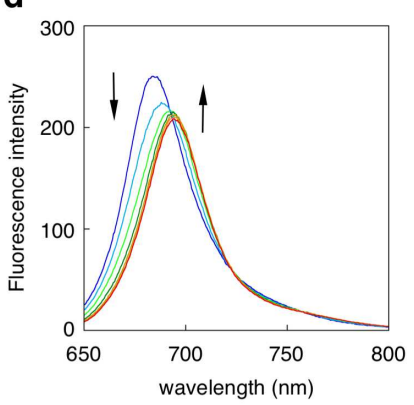

h

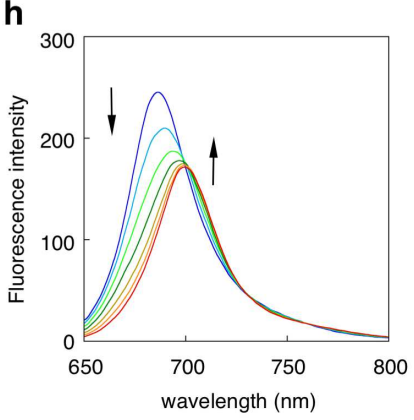

Figure 4. Fluorescence spectral changes of probes 8-11 (from left to right) upon addition of $\mathrm{ZnCl}_{2}$ (a-d) or $\mathrm{CdCl}_{2}(\mathbf{e}-\mathbf{h})$. Measurement conditions: [probe] $=5 \mu \mathrm{M}(\mathbf{9}, \mathbf{1 0}, \mathbf{1 1})$ or $10 \mu \mathrm{M}(\mathbf{8}), 50 \mathrm{mM}$ HEPES $(\mathrm{pH} 7.4) / \mathrm{MeOH}=1: 1,25^{\circ} \mathrm{C}$.

Figure 4 shows the fluorescence spectra changes of 8-11 in titrations with $\mathrm{Zn}(\mathrm{II})$ and $\mathrm{Cd}(\mathrm{II})$ under aqueous $\mathrm{MeOH}$ conditions (50 mM HEPES $(\mathrm{pH} 7.4) / \mathrm{MeOH}=1: 1)$. Xanthene 9 and pyronine 10 exhibited the largest emission red-shifts $(\Delta F=27$ and $25 \mathrm{~nm}$, respectively) in the titration with $\mathrm{Zn}(\mathrm{II})$, while the wavelength shift of coumarin 8 was rather small $(\Delta F=5 \mathrm{~nm}$ ) (Table 2). Sipyronine 11 exhibited a moderate emission red-shift $(\Delta \mathrm{F}=10 \mathrm{~nm})$ in the near-infrared wavelength region $(685 \rightarrow 695 \mathrm{~nm})$ upon coordination with $\mathrm{Zn}(\mathrm{II})$. The coordination of $\mathrm{Cd}(\mathrm{II})$ also induced a clear emission red-shift in the case of $\mathbf{9 , 1 0}$, and $\mathbf{1 1}(\Delta F=27,28$, and $14 \mathrm{~nm}$, respectively), while the wavelength shift of 8 was rather small $(\Delta F=4 \mathrm{~nm})$ as observed in the $\mathrm{Zn}$ (II) titration. It should be noted that all the probes showed bathochromic absorption shifts upon coordination with $\mathrm{Zn}$ (II) 
and Cd(II) (Figure S5, Table S3). Interestingly, the binding affinity for Zn(II) varied depending on the fluorophore (Table S2). That is, anthracene 5 had the highest binding affinity $\left(K_{a}=2.7 \times 10^{6}\right.$ $\left.\mathrm{M}^{-1}\right)$, which is $c a$. 4- and $c a$. 50-fold stronger than that of xanthene $9\left(K_{a}=6.5 \times 10^{5} \mathrm{M}^{-1}\right)$ and pyronine $10\left(K_{a}=5.0 \times 10^{4} \mathrm{M}^{-1}\right)$, respectively. This binding affinity order was almost the same as that with $\mathrm{Cd}(\mathrm{II})$ (Table S2). The weak binding affinities of pyronine $\mathbf{1 0}$ could be ascribed to the long distance between the two 1,8-methylene carbons on the pyronine fluorophore (Figure 3), which may reduce the conformational flexibility of the BPTN ligand required for the coordination.

Table 2. Summary of fluorescence emission shifts of probes $\mathbf{5}$ and $\mathbf{8 - 1 1}$ upon addition of various metal ions. ${ }^{\mathrm{a}}$

\begin{tabular}{|c|c|c|c|c|c|c|c|c|c|c|}
\hline Probe & $\mathrm{Cr}^{3+}$ & $\mathrm{Mn}^{2+}$ & $\mathrm{Co}^{2+}$ & $\begin{array}{c}\mathrm{Ni}^{2+} \\
(1.63 \AA)^{\mathrm{b}}\end{array}$ & $\begin{array}{c}\mathrm{Cu}^{2+} \\
(1.40 \AA)^{\mathrm{b}}\end{array}$ & $\begin{array}{c}\mathrm{Zn}^{2+} \\
(1.39 \AA)^{\mathrm{b}}\end{array}$ & $\begin{array}{c}\mathrm{Ag}^{+} \\
(1.72 \AA)^{\mathrm{b}}\end{array}$ & $\begin{array}{c}\mathrm{Cd}^{2+} \\
(1.62 \AA)^{\mathrm{b}}\end{array}$ & $\begin{array}{c}\mathrm{Hg}^{2+} \\
(1.70 \AA)^{\mathrm{b}}\end{array}$ & $\begin{array}{c}\mathrm{Pb}^{2+} \\
(2.02 \AA)^{\mathrm{b}}\end{array}$ \\
\hline $\mathbf{5}$ & $-^{\mathrm{c}}$ & $-^{\mathrm{c}}$ & $<3$ & $<3$ & $<3$ & 13 & 69 & 63 & 45 & 33 \\
\hline $\mathbf{8}$ & $-^{\mathrm{c}}$ & $-^{\mathrm{c}}$ & $<3$ & $<3$ & $<3$ & 5 & $<3$ & 4 & $<3$ & $<3$ \\
\hline $\mathbf{9}$ & $-^{\mathrm{c}}$ & $-^{\mathrm{c}}$ & $<3$ & $<3(3)^{\mathrm{d}}$ & $25(24)^{\mathrm{d}}$ & $27(25)^{\mathrm{d}}$ & $8(25)^{\mathrm{d}}$ & $27(25)^{\mathrm{d}}$ & 34 & $<3$ \\
\hline $\mathbf{1 0}$ & $-^{\mathrm{c}}$ & $-^{\mathrm{c}}$ & $<3$ & $<3$ & 30 & 25 & 15 & 28 & 35 & $<3$ \\
\hline
\end{tabular}

${ }^{a}$ Fluorescence titration was conducted under aqueous $\mathrm{MeOH}$ conditions (50 mM HEPES ( $\left.\left.\mathrm{pH} 7.4\right) / \mathrm{MeOH}=1: 1\right)$.

${ }^{b}$ Value in the parenthesis is the Van der Waals radius of metal ion. ${ }^{c}$ Negligible fluorescence intensity change and emission shift were observed. ${ }^{\mathrm{d}}$ Value in the parenthesis is the fluorescence emission shift observed under aqueous buffer conditions (50 mM HEPES, pH 7.4).

We further investigated the fluorescence sensing properties of the probes toward other metal ions. All titrations were carried out under aqueous $\mathrm{MeOH}$ conditions (50 mM HEPES (pH $7.4) / \mathrm{MeOH}=1: 1)$ to avoid aggregation of the metal complex. Table 2 and Figure S6 summarize the maximum emission red-shifts $(\Delta F)$ of $\mathbf{5}$ and 8-11 at the saturation point of the titration with metal ions. All the probes except for coumarin 8 showed significant emission red-shifts upon coordination with $4 \mathrm{~d}$ - and 5d-block metal ions such as $\mathrm{Ag}(\mathrm{I}), \mathrm{Cd}(\mathrm{II})$, and $\mathrm{Hg}(\mathrm{II})$. In the titration with $\mathrm{Cu}(\mathrm{II})$, 9-11 also showed significant emission red-shifts along with a large decrease in the fluorescence (Figure S9-S11). Conversely, anthracene 5 did not show an emission shift upon binding with $\mathrm{Cu}(\mathrm{II})$ (Figure S7), even though a substantial bathochromic shift $(\Delta \mathrm{Abs}=6 \mathrm{~nm})$ was observed in the absorption titration with $\mathrm{Cu}(\mathrm{II})$ (Table S3). This observation could be explained by a very weak fluorescence emission of the copper complex of $\mathbf{5}$ as a result of the strong quenching effect of $\mathrm{Cu}(\mathrm{II})$. Similarly, $\mathbf{5}$ and $\mathbf{1 1}$ showed negligible emission red-shifts in the titration with $\mathrm{Ni}(\mathrm{II})$ and $\mathrm{Co}(\mathrm{II})$, while their absorption wavelengths were clearly shifted $(\Delta \mathrm{Abs}=6-15 \mathrm{~nm})($ Table $\mathrm{S} 3)$. The 
metal ion titration was also conducted under aqueous buffer conditions (50 mM HEPES, pH 7.4) using the highly water-soluble probe $\mathbf{9}$. Probe 9 exhibited a large emission red-shift upon binding with $\mathrm{Cu}(\mathrm{II}), \mathrm{Zn}(\mathrm{II}), \mathrm{Ag}(\mathrm{II})$, and $\mathrm{Cd}(\mathrm{II})$ (Table S2). The small emission red-shifts of coumarin 8 toward all the metal ions tested (Figure S8) might be attributed to the formation of an intramolecular charge transfer excited state, which cancels out the change in the photophysical property of the coumarin fluorophore induced by AM-contact. Another explanation for the small emission shifts of $\mathbf{8}$ might be an intrinsic low contact ability of the coumarin fluorophore because of its low electron density, as suggested by Hancock et al. ${ }^{20}$

\section{$X$-ray structures of the metal ion complexes}

The structures of the metal ion complexes of probe 5 were analyzed by X-ray crystallography (Figure 5, Figure S12, Table S4). The zinc complex 5-Zn(II) has a square pyramidal coordination geometry and the five nitrogen atoms are coordinated to the $\mathrm{Zn}$ (II) ion (Figure 5a). The distance between $\mathrm{Zn}$ (II) and the adjacent C9 carbon atom is $2.96 \AA$, which is shorter than the sum of the van der Waals radii of $\mathrm{Zn}(\mathrm{II})(1.39 \AA)$ and the aromatic carbon $\left(1.77 \AA\right.$ ) (Table S5). ${ }^{21}$ Figure $5 \mathrm{~b}$ is the cross-sectional view of the $5-\mathrm{Zn}$ (II) complex, which clearly shows the van der Waals contact between the $\mathrm{Zn}(\mathrm{II})$ ion and the $\mathrm{C} 9$ carbon. Interestingly, this close contact induces bending of the C9- $\mathrm{H}$ bond by $6.9^{\circ}$ from the $\pi$ plane of the anthracene ring toward the side opposite of $\mathrm{Zn}(\mathrm{II})$. Van der Waals contact between the metal ion and fluorophore was also observed in 5-Cd(II) and 5$\operatorname{Ag}(\mathrm{I})$ (Figure 5c,d). 5-Cd(II) has a square pyramidal coordination geometry, and the distance between $\mathrm{Cd}(\mathrm{II})$ and the $\mathrm{C} 9$ carbon atom is $3.01 \AA$, which is shorter than the sum of the van der Waals radii of $\mathrm{Cd}(\mathrm{II})(1.58 \AA)$ and the aromatic carbon $(1.77 \AA)$. 5- $\mathrm{Ag}(\mathrm{I})$ has a trigonal pyramidal coordination geometry, in which one aliphatic nitrogen atom of the BPTN ligand does not coordinate to $\operatorname{Ag}(\mathrm{I})$. Although the distance between $\mathrm{Ag}(\mathrm{I})$ and the $\mathrm{C} 9$ carbon atom is rather long (3.28 $\AA$ ), they still form a van der Waals contact owing to the large van der Waals radius of $\operatorname{Ag}(\mathrm{I})(1.72 \AA)$. In contrast to $5-\mathrm{Zn}(\mathrm{II})$, the bending of the $\mathrm{C} 9-\mathrm{H}$ bond from the $\pi$ plane of the anthracene ring in 5-Cd(II) and 5- $\mathrm{Ag}(\mathrm{I})$ is negligible. 5-Cu(II) has a square planer coordination geometry, in which the distance between $\mathrm{Cu}(\mathrm{II})$ and the $\mathrm{C} 9$ carbon atom is $3.14 \AA$ (Figure 5e). Although this distance is only slightly shorter than the sum of the van der Waals radii of $\mathrm{Cu}(\mathrm{II})$ (1.40 $\AA$ ) and the aromatic carbon $(1.77 \AA)$, the coordination of $\mathrm{Cu}(\mathrm{II})$ induced the substantial absorption shift $(\triangle \mathrm{Abs}=6 \mathrm{~nm})$ of 5 (Table S3). It is also worth noting that the conformation of the BPTN ligand is sufficiently flexible to coordinate metal ions with different radii; the distance between the N3' nitrogen and N9' nitrogen of the BPTN unit varied from 4.22 to $4.54 \AA$ depending on the metal ion (Table S5), 
accommodating the coordinated metal ions at the close position of the anthracene ring to induce 224 the emission red-shift.

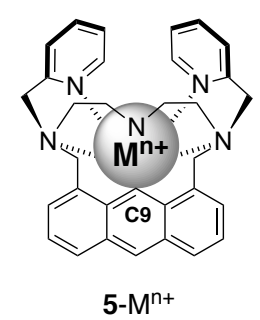

C

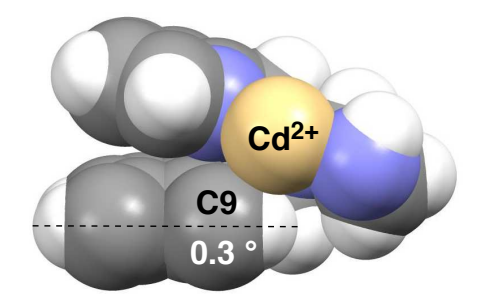

a

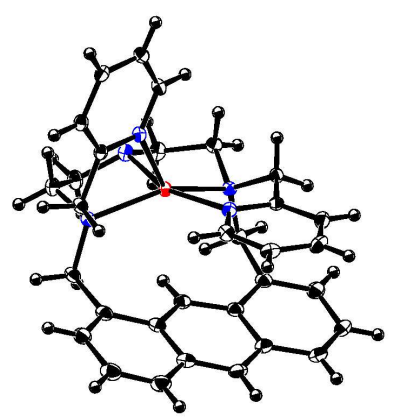

d

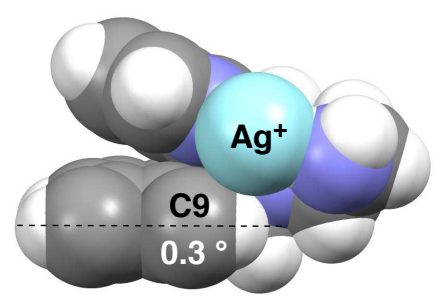

b

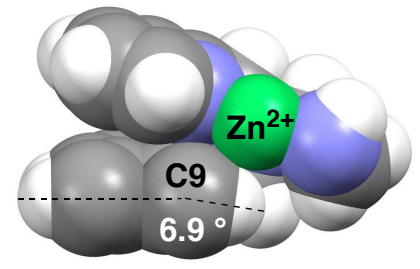

e

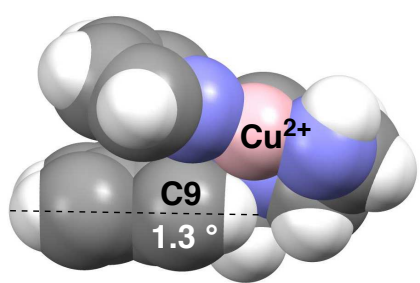

Figure 5. X-ray structures of the metal ion complexes 5-M $\mathrm{M}^{\mathrm{n}+}\left(\mathrm{M}^{\mathrm{n}+}=\mathrm{Zn}^{2+}, \mathrm{Cd}^{2+}, \mathrm{Ag}^{+}\right.$, or $\left.\mathrm{Cu}^{2+}\right)$. (a) ORTEP diagram (50\% probability ellipsoids) of $5-\mathrm{Zn}^{2+}\left(\mathrm{C}_{32} \mathrm{H}_{32} \mathrm{~N}_{4} \mathrm{O}_{8} \mathrm{Cl}_{2} \mathrm{Zn}\right)$. The perchlorate anions are omitted for clarity. (b-e) Cross-sectional views of the metal ion complexes of 5.

\section{Computational analysis of AM-contact sensing}

To understand the theoretical mechanism of AM-contact sensing, we performed electronicstructure calculations for the selected probes and their zinc ion complexes. The low-lying excited states of xanthene probe 9 and its zinc complex 9-Zn(II) were initially calculated with the timedependent density functional theory (TDDFT) method (Table 3). The $\mathrm{S}_{0} \rightarrow \mathrm{S}_{1}$ transition energy of 9 was $\Delta \mathrm{E}=2.978 \mathrm{eV}$ in water, which is smaller than that of $9-\mathrm{Zn}(\mathrm{II})(\Delta \mathrm{E}=2.733 \mathrm{eV})$. This result reproduces the experimentally observed red-shift of the absorption band $[2.426 \mathrm{eV}(511 \mathrm{~nm}) \rightarrow$ $2.380 \mathrm{eV}(521 \mathrm{~nm})]$ induced by $\mathrm{Zn}(\mathrm{II})$ ion coordination. Table S6 summarizes the HOMO and LUMO energy levels of 9 and 9-Zn(II). The HOMO-LUMO energy gap of $9(\Delta \mathrm{E}=2.978 \mathrm{eV})$ decreases upon complexation with $\mathrm{Zn}(\mathrm{II})$ in water $(\Delta \Delta \mathrm{E}=0.245 \mathrm{eV})$. A TDDFT calculation was also conducted by replacing the zinc ion of $9-\mathrm{Zn}$ (II) with a positive charge (PC) of $+1.0 e$ (1PC) and $+2.0 e\left(2 \mathrm{PC}\right.$ ) (Table 3). The $\mathrm{S}_{0} \rightarrow \mathrm{S}_{1}$ transitions of $9+\mathrm{PC}(1.0)$ and $9+2 \mathrm{PC}(2.0)$ were calculated to be 2.827 and $2.360 \mathrm{eV}$, respectively, under vacuum conditions, which are lower than that of 9 $(\Delta \mathrm{E}=3.015 \mathrm{eV})$. The decrease of the $\mathrm{S}_{0} \rightarrow \mathrm{S}_{1}$ transition energy was also induced by the coordination of other metal cations such as $\mathrm{Na}(\mathrm{I})$ and $\mathrm{Ca}(\mathrm{II})$ to 9 (Table S7). These results all suggest that electrostatic interaction with the positively charged $\mathrm{Zn}$ (II) influences the photophysical property 
of 9, leading to the coordination-induced emission red-shift in 9-Zn(II). This prediction is consistent with that previously reported for the $\mathrm{Cd}(\mathrm{II})$ and $\mathrm{Ag}(\mathrm{I})$ complexes of the Type-I probes. ${ }^{17}$

Table 3. Summary of the $\mathrm{S}_{0}-\mathrm{S}_{1}$ excitation state of the probes with or without zinc ion/positive charge (PC) coordination.

\begin{tabular}{|c|c|c|c|c|c|}
\hline \multirow{2}{*}{ species } & \multirow{2}{*}{$\begin{array}{l}\text { optimized ge- } \\
\text { ometry }^{\mathrm{a}}\end{array}$} & \multirow{2}{*}{ environment } & \multicolumn{3}{|c|}{$\mathrm{S}_{0}-\mathrm{S}_{1}$ excitation } \\
\hline & & & $\Delta \mathrm{E}(\mathrm{eV})$ & $\lambda(\mathrm{nm})$ & $f$ \\
\hline 9 & 9 & water $^{\mathrm{b}}$ & 2.978 & 416.3 & 0.808 \\
\hline 9+Zn(II) & 9 & water $^{b}$ & 2.733 & 453.6 & 0.618 \\
\hline 9 & 9 & vacuum & 3.015 & 411.2 & 0.661 \\
\hline $9+\mathrm{PC}(0.0)$ & 9-Zn(II) & vacuum & 3.003 & 412.9 & 0.570 \\
\hline $9+\mathrm{PC}(1.0)$ & 9-Zn(II) & vacuum & 2.827 & 438.6 & 0.491 \\
\hline $9+\mathrm{PC}(2.0)$ & 9-Zn(II) & vacuum & 2.360 & 525.3 & 0.098 \\
\hline 5 & 5 & water $^{\mathrm{b}}$ & 3.596 & 344.8 & 0.163 \\
\hline $\mathbf{5}+\mathrm{Zn}(\mathrm{II})$ & 5 & water $^{\mathrm{b}}$ & 3.520 & 352.2 & 0.152 \\
\hline 5 & 5 & vacuum & 3.626 & 341.9 & 0.130 \\
\hline $5+\mathrm{PC}(0.0)$ & $5-\mathrm{Zn}(\mathrm{II})$ & vacuum & 3.549 & 349.3 & 0.113 \\
\hline $5+P C(1.0)$ & $5-\mathrm{Zn}(\mathrm{II})$ & vacuum & 3.576 & 346.7 & 0.114 \\
\hline $5+\mathrm{PC}(2.0)$ & $5-\mathrm{Zn}(\mathrm{II})$ & vacuum & 3.555 & 348.8 & 0.112 \\
\hline
\end{tabular}

${ }^{\mathrm{a}}$ Geometry optimization was performed for a molecule in vacuum. ${ }^{\mathrm{b}}$ The solvent effect was taken into account using the polarizable continuum model.

In the case of the anthracene probe 5 , the $S_{0} \rightarrow S_{1}$ transition energy in water was calculated to be $3.596 \mathrm{eV}$ (Table 3). This value was reduced to $3.520 \mathrm{eV}$ in the zinc complex $5-\mathrm{Zn}$ (II). This trend in the narrowing of the energy gap agrees with the experimentally observed red-shift of the absorption band $[3.378 \mathrm{eV}(367 \mathrm{~nm}) \rightarrow 3.324 \mathrm{eV}(373 \mathrm{~nm})]$ induced by zinc coordination. In the calculation with positive charge, the $\mathrm{S}_{0} \rightarrow \mathrm{S}_{1}$ transition energy of 5-PC(1.0) was calculated to be $3.576 \mathrm{eV}$ under vacuum conditions, which is lower than that of $5(\Delta \mathrm{E}=3.626 \mathrm{eV})$ in vacuum. This result is consistent with the emission red-shift observed for the zinc coordination of $\mathbf{5}$. Interestingly, when the calculation was conducted for 5-PC(0.0), which possesses the optimized geometry of 5$\mathrm{Zn}$ (II) with a bent $\mathrm{C} 9-\mathrm{H}$ bond, the $\mathrm{S}_{0} \rightarrow \mathrm{S}_{1}$ transition energy was calculated to be $3.549 \mathrm{eV}$. This value is smaller than that of 5-PC(1.0) with the same geometry $(\Delta \mathrm{E}=3.576 \mathrm{eV})$, contradicting the experimental result of the zinc coordination of 5. This implies that the emission red-shift of $\mathbf{5}$ can be induced not only by the electronic perturbation of the positively charged zinc ion, but also by the deformation of the anthracene ring as observed in the X-ray crystallography of 5-Zn(II) (Figure 


\section{Differential sensing of metal ions}

Although the Type-III probes bearing a BPTN ligand can sense various metal ions, discrimination of individual metal ions is also of great importance in the fields of applied chemistry such as environmental monitoring, metal ion toxicology, and bioinorganic chemistry. In recent years, several types of fluorescence sensor arrays capable of distinguishing sets of metal ions have been reported. ${ }^{23-26}$ These systems employ a series of cross-reactive sensors for metal ions, which produce a data set of the fluorescence signal change. Applying statistical analysis to the data enables unambiguous identification of the metal ions. We expected that the probes using AM-contact sensing would also be applicable to differential metal ion detection. In particular, we aimed to construct a one-pot multicolor fluorescence sensing system comprising a set of the probes, which fluoresce at different wavelengths. It was anticipated that this type of sensing system would allow us to avoid repeated measurements, which are usually necessitated in sensor array detection.

a

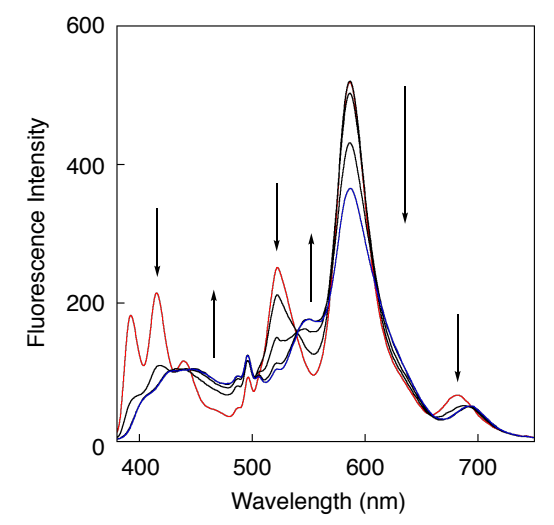

b

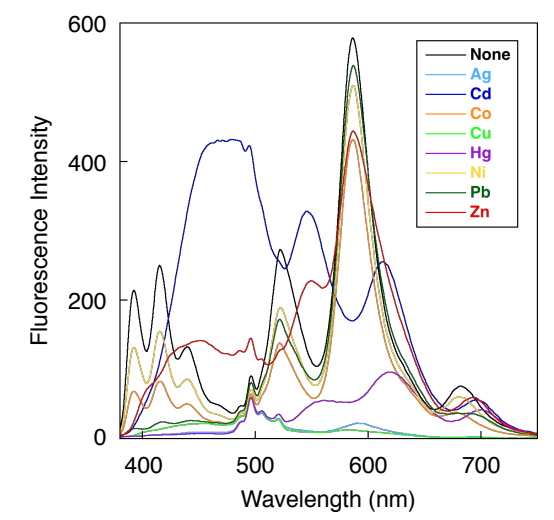

C

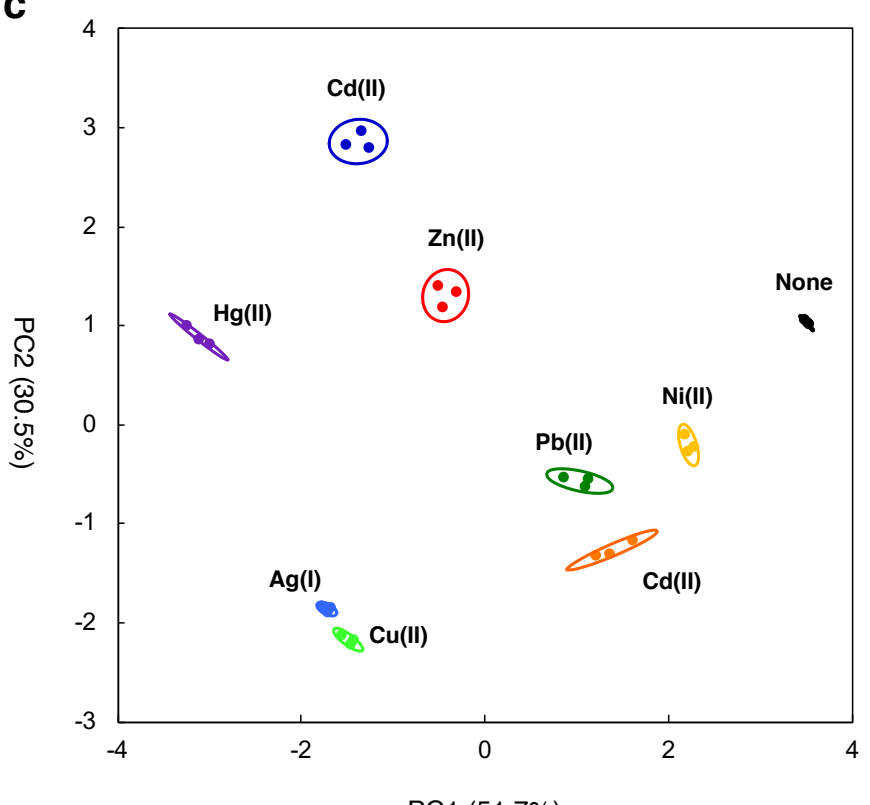

PC1 (51.7\%)

283 Figure 6. Multicolor fluorescence sensing of metal ions. (a) Fluorescence spectral change of the set of probes 5, 9, 10, and 11 upon addition of $\mathrm{ZnCl}_{2}(0-30 \mu \mathrm{M})$. (b) Fluorescence spectral change 
of the set of probes upon addition of various metal ions $(30 \mu \mathrm{M})$. (c) PCA plot of the two principle components (PC1 and PC2) for eight metal ions $(30 \mu \mathrm{M})$. Measurement conditions: $[5,9,10]=2$ $\mu \mathrm{M},[\mathbf{1 1}]=4 \mu \mathrm{M}, 50 \mathrm{mM}$ HEPES $(\mathrm{pH} 7.4) / \mathrm{MeOH}=1: 1,25^{\circ} \mathrm{C} . \lambda_{\text {ex }}=254 \mathrm{~nm}$.

As a proof-of-concept experiment, we employed the probes 5, 9, 10, and 11 for multicolor metal ion sensing. A solution containing the set of probes $(2 \mu \mathrm{M}$ of $\mathbf{5 , 9}$, and $\mathbf{1 0}$, and $4 \mu \mathrm{M}$ of $\mathbf{1 1})$ displayed a complicated emission spectrum from 380 to $750 \mathrm{~nm}$ (Figure 6a) when excited at $254 \mathrm{~nm}$. The addition of $\mathrm{Zn}$ (II) $(0-30 \mu \mathrm{M})$ induced a clear spectral change as a result of the dual emission responses of each probe to provide a unique emission spectrum, which is distinct from the initial spectrum. Titration with other metal ions such as $\mathrm{Co}(\mathrm{II}), \mathrm{Ni}(\mathrm{II}), \mathrm{Cu}(\mathrm{II}), \mathrm{Cd}(\mathrm{II}), \mathrm{Ag}(\mathrm{I}), \mathrm{Hg}(\mathrm{II})$, and $\mathrm{Pb}$ (II) also provided the unique emission spectral changes (Figure 6b). Each spectral pattern was recorded at eight wavelengths to provide emission ratio values of $F_{450} / F_{414}, F_{550} / F_{525}, F_{615} / F_{589}$, and $F_{690} / F_{679}$, as well as emission intensity change $F / F_{\mathrm{o}}$ values at $414,525,589$, and $679 \mathrm{~nm}$ as a set of signal outputs. By analyzing these data set using PCA, we were able to differentiate the eight metal ions at $30 \mu \mathrm{M}$ on a two-dimensional dispersion graph (Figure 6c). PCA analysis was further applied to the output data of the concentration-dependent fluorescence spectral change. The two-dimensional dispersion graph revealed that the probe set can distinguish the four metal ions $\mathrm{Zn}(\mathrm{II}), \mathrm{Cu}(\mathrm{II})$, $\mathrm{Cd}(\mathrm{II})$, and $\mathrm{Hg}(\mathrm{II})$ in concentrations from 1 to $30 \mu \mathrm{M}$ (Figure $\mathrm{S} 13$ ).

\section{Ratio imaging of metal ions in live cells}

We next set out to examine the utility of the xanthene-type probe for ratiometric fluorescence imaging of metal ions in living cells (Figure 7). For this purpose, we designed probe 12, which possesses the lipophilic O-p-acetoxy benzyl and N-ethoxyethyl groups (Figure 7a). These substituents were introduced to increase the membrane permeability of $\mathbf{9}$. We confirmed that probe $\mathbf{1 3}$, which is obtained from $\mathbf{1 2}$ by hydrolysis, exhibits a clear dual emission change and a significant increase of the fluorescence intensity ratio $\left(F_{550 \mathrm{~nm}} / F_{520 \mathrm{~nm}}\right)$ upon addition of $\mathrm{ZnCl}_{2}$ under the neutral aqueous solution (50 mM HEPES, $100 \mathrm{mM} \mathrm{NaCl}, \mathrm{pH} 7.4$ ) (Figure 7b, 7c). The binding affinity of 13 toward $\mathrm{Zn}$ (II) was evaluated to be $6.1 \times 10^{6} \mathrm{M}^{-1}$ under the same aqueous conditions (Figure S14). When HeLa cells were treated with $5 \mu \mathrm{M}$ of 12 in HBS buffer, bright fluorescence from the xanthene fluorophore was observed inside the cells (Figure 7d). It was evident that non-fluorescent 12 penetrated into the cells and was hydrolyzed to fluorescent $\mathbf{1 3}$ by intracellular esterase. Treatment of the cells with $5 \mu \mathrm{M}$ of zinc chloride in the presence of pyrithione $(100 \mu \mathrm{M})$ induced a

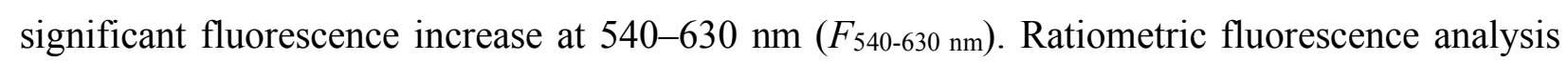
revealed that the ratio value $\left(F_{540-630 \mathrm{~nm}} / F_{500-530 \mathrm{~nm}}\right)$ gradually increased in a time-dependent manner. 
319 Live-cell imaging was further conducted for other metal ions such as $\mathrm{Cu}(\mathrm{II}), \mathrm{Cd}(\mathrm{II})$, and $\mathrm{Hg}(\mathrm{II})$. 320 As shown in Figure 7e, the fluorescence ratio was changed inside the cells upon the addition of 5 $321 \mu \mathrm{M}$ of $\mathrm{Cd}(\mathrm{II})$ and $\mathrm{Cu}(\mathrm{II})$, while the change was rather small in the case of $\mathrm{Hg}(\mathrm{II})$. These results 322 demonstrated that AM-contact sensing works in living cells to enable ratio imaging of the metal 323 ions.

a

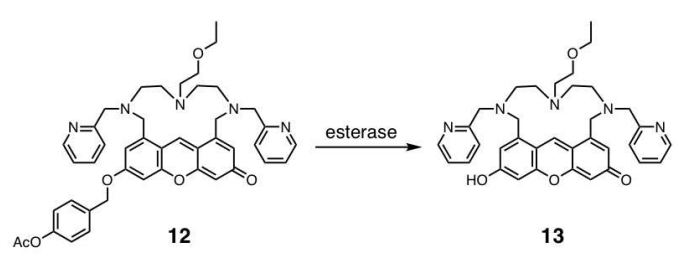

13 b

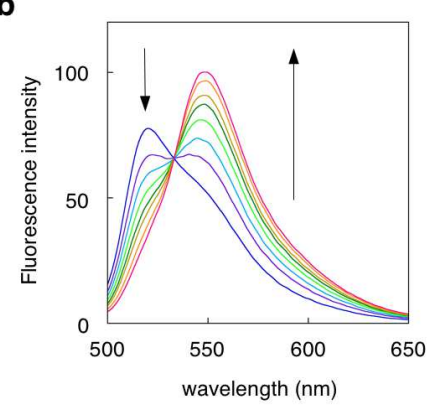

c

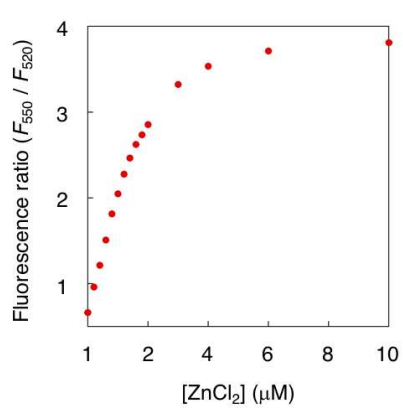

d

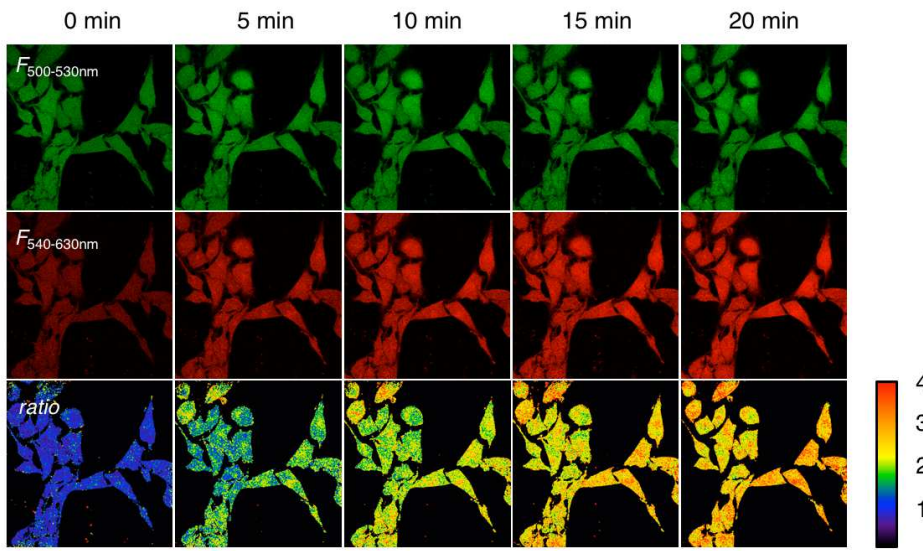

e

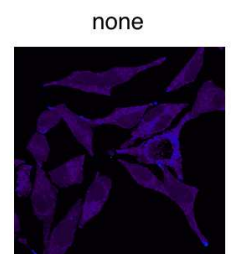

$\mathrm{Cd}(\mathrm{II})$

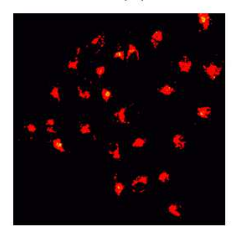

$\mathrm{Cu}(\mathrm{II})$

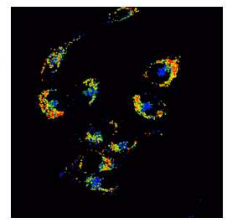

$\mathrm{Hg}(\mathrm{II})$

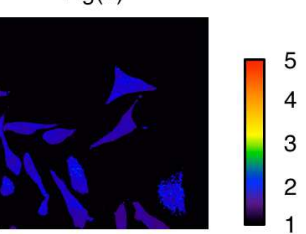

Figure 7. Ratiometric fluorescence detection of metal ions in living cells. (a) Structures of probe

12 and its hydrolyzed product 13. (b) Fluorescence spectral change of 13 upon addition of $\mathrm{ZnCl}_{2}$.

Measurement conditions: $[13]=1 \mu \mathrm{M},\left[\mathrm{ZnCl}_{2}\right]=0,0.2,0.4,0.6,0.8,1.0,1.4,2 \mu \mathrm{M}, 50 \mathrm{mM}$

(c) Plot of the fluorescence intensity ratio

$\left(F_{550 \mathrm{~nm}} / F_{520 \mathrm{~nm}}\right)$ of $\mathbf{1 3}$ upon addition of $\mathrm{ZnCl}_{2}$. (d) Time-lapse images of $\mathrm{Zn}(\mathrm{II})$ inside HeLa cells.

The cells were incubated with probe $12(5 \mu \mathrm{M})$ followed by the treatment with $\mathrm{ZnCl}_{2}(5 \mu \mathrm{M})$ in the presence of pyrithione $(100 \mu \mathrm{M})$. The ratio images were obtained from the imaging data ac-

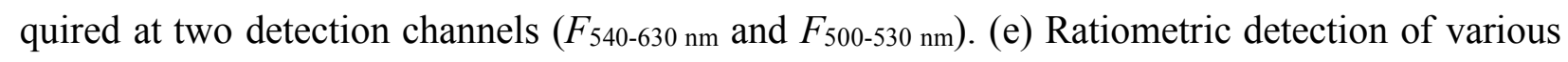
metal ions in HeLa cells. The fluorescence images were acquired at $5 \mathrm{~min}$ after the treatment of the cells with each metal ion $(5 \mu \mathrm{M})$ in the presence of pyrithione $(100 \mu \mathrm{M})$.

\section{Discussion}

Chelation-induced PCT is the most widely used sensing mechanism in the development of ratiometric fluorescent probes for metal ions. In a probe implemented with this mechanism, the 
fluorophore must have a heteroatom $(\mathrm{N}, \mathrm{O}, \mathrm{S}$, etc.) directly connected to or incorporated in its $\pi$ electron system, which undergoes a change in its electronic structure upon coordination with a metal ion, resulting in an emission wavelength shift. Unfortunately, this structural requirement limits the choice of fluorophores available for the ratiometric fluorescence sensing of metal ions. FRET is less frequently employed in the design of ratiometric fluorescence probes for metal ions because the FRET system requires two fluorophores within one molecule, making it difficult to design a probe with the proper function. The large molecular size of the FRET-type probe also inhibits its aqueous solubility and cell membrane permeability in live-cell imaging. In contrast to these existing systems, AM-contact sensing does not have such structural limitations and requirements because it utilizes the spatial proximity between the fluorophore and metal ion, allowing a variety of fluorophores to be employed in a simple molecular architecture. Indeed, we clearly demonstrated in this study that AM-contact sensing could operate with various tricyclic fluorophores bearing a BPTN ligand.

Our previous results ${ }^{17,22}$ and reports by Czarnik ${ }^{27}$ and Hancock ${ }^{20,28,29}$ suggested that the contactinduced emission shift was limited to rather large $4 \mathrm{~d}$ - and 5d-block metal ions such as $\mathrm{Cd}(\mathrm{II})$ and $\operatorname{Ag}(\mathrm{I})$. In this paper, we demonstrated for the first time that AM-contact sensing could also work with the smaller 3d-block metal ions such as $\mathrm{Zn}$ (II) and $\mathrm{Cu}(\mathrm{II})$. This was possible due to the molecular design of the Type-III probe, which employs the semicyclic BPTN as a metal ligand unit. X-ray crystallography of the metal ion complexes of 5 revealed that the BPTN ligand places a metal ion on the upper edge of the anthracene $\pi$-plane to facilitate van der Waals contact between them. Computational analysis suggested that electrostatic interaction between the fluorophore and the adjacent metal ion largely contributes to the emission red-shift (Figure 5). It is reasonable to assume that this electrostatic interaction can effectively work in a coordination complex wherein the metal ion is located close to the fluorophore, within their van der Walls radii. The computational analyses further suggested that the bend of the $\mathrm{C} 9-\mathrm{H}$ bond in the anthracene ring, which was observed in the zinc complex of 5, also contributes to the emission red-shift as a result of the change in the electronic structure of the fluorophore. We propose at this stage that these two structural perturbations (i.e., electrostatic interaction with metal ion and deformation of aromatic ring) contribute to the emission shift in AM-contact sensing using the Type-III probes.

We have demonstrated the utility of AM-contact sensing in two analytical applications: multicolor differential sensing of metal ions based on PCA analysis and ratio imaging of metal ions in living cells. Both applications took full advantage of the unique properties of AM-contact sensing, including high compatibility with various fluorophores, broad applicability to different metal ions, and a clear ratiometric emission change. We expect that further refinement of the probe architecture, especially in the metal binding unit, will provide more sophisticated fluorescent probes with larger emission shifts and higher metal ion selectivities. We also envision that AM-contact sensing will be applicable to a broader range of metal ions, including alkaline and alkaline-earth metal ions, under 
various analytical settings. ${ }^{30}$ Finally, we envisage that the utility of AM-contact sensing can be further extended to the dual-emission sensing of anions ${ }^{31}$ and organic molecules ${ }^{32}$ if their coordination to the metal ion can perturb close contact between the fluorophore and the coordinated metal ion.

\section{Methods}

\section{Metal ion titration}

Fluorescence spectrum was recorded on PerkinElmer LS-55 spectrofluorophotometer. Absorption spectrum was measured using Shimadzu UV-2600 spectrophotometer. In typical titration experiment, probe solution $(25 \mu \mathrm{M}$ of $5,10 \mu \mathrm{M}$ of $\mathbf{8}$, or $5 \mu \mathrm{M}$ of $\mathbf{9}, \mathbf{1 0}, \mathbf{1 1})$ in $50 \mathrm{mM}$ HEPES buffer $(\mathrm{pH}=7.4)$ : $\mathrm{MeOH}=1: 1$ was titrated with aqueous stock solution of metal ion in a quartz cell at $25^{\circ} \mathrm{C}$. The fluorescence and absorption spectra were measured at $5 \mathrm{~min}$ after addition of the metal ion at each titration point. In the fluorescence titration, probes $\mathbf{5 , ~ 8 , ~ 9 , ~ 1 0 , ~} 11$ were excited at 365, 410, 488, 578, $674 \mathrm{~nm}$, respectively. The plot of the fluorescence intensity at the maximum emission wavelength was analyzed by nonlinear least-square curve fitting to obtain the binding constant $\left(K_{a}, \mathrm{M}^{-1}\right)$.

\section{Determination of fluorescence quantum yield $(\Phi)$}

Fluorescence quantum yields $(\Phi)$ of the probes were determined in $50 \mathrm{mM}$ HEPES buffer $(\mathrm{pH}=7.4)$ : methanol $=1: 1$ using quinine sulfate $(\Phi=0.55)$ for $\mathbf{5}$ and $\mathbf{8}$, fluorescein $(\Phi=0.95)$ for $\mathbf{9}$, Rhodamine 6G $(\Phi=0.95)$ for $\mathbf{1 0}$ and NileBlue $(\Phi=0.95)$ for $\mathbf{1 1}$ as the fluorescence quantum yield standards.

\section{Multicolor fluorescence sensing of metal ions}

Metal ion titration was carried out in aqueous-methanol solvent $(50 \mathrm{mM}$ HEPES buffer $(\mathrm{pH}=7.4)$ : methanol $=1: 1)$ containing the set of the probes $(2 \mu \mathrm{M}$ of $5, \mathbf{9}, 10$ and $4 \mu \mathrm{M}$ of 11). After addition of the metal ions, the fluorescence spectra were recorded on PerkinElmer LS-55 spectrofluorophotometer at $25{ }^{\circ} \mathrm{C}\left(\lambda_{\mathrm{ex}}=254 \mathrm{~nm}\right)$. Principal component analysis (PCA) was performed with Microsoft Excel 2011 using the data set of the emission intensity change $\left(F / F_{0}\right.$ at $\left.414,525,589,679 \mathrm{~nm}\right)$ and the emission ratios $\left(F_{450} / F_{414}, F_{550} / F_{525}, F_{615} / F_{589}, F_{690} / F_{679}\right)$.

\section{X-ray crystallography}

All the metal ion complexes of 5 were crystallized from $\mathrm{MeOH} / \mathrm{CH}_{3} \mathrm{CN}=3: 1$ at $30{ }^{\circ} \mathrm{C}$. The X-ray data were collected on a Bruker AXS APEX II diffractometer with graphite monochromated MoKa radiation $(\lambda=0.71069 \AA)$. The structures were solved by the direct method and refined anisotropically for non-hydrogen atoms by full-matrix least-squares calculations. The crystallographic calculations were performed by using the Crystal structure software package of the Rigaku Corporation. The CCDC deposition numbers of the crystallographic data are as follows: 5-Zn(II); 1993118, 5-Cd(II); 1993119, 5-Ag(I); 1993120, 5-Cu(II); 1993121. 
Density functional theory (DFT) was applied to investigate the electronic origin of the spectral shift induced in the metal complexes. In the calculation, the CAM-B3LYP functional was applied to describe the exchange-correlation term. This calculation was carried out for molecules in a vacuum with the default computational parameters in Gaussian09. In order to calculate the excited states, the TDDFT method was applied to obtain the lower 20 states. The Kohn-Sham orbitals were described with the Gaussian basis sets. For all the elements, we used the $6-31 G(d, p)$ and the $6-31+G(d, p)$ basis sets for optimization. The solvent effect was taken into account by using the polarized continuum model for water as the solvent.

\section{Cell culture}

HeLa cells were cultured in high-glucose Dulbecco's Modified Eagle medium (DMEM, 4.5 g of glucose/L, Sigma-Aldrich) supplemented with 10\% fetal bovine serum (FBS), penicillin (100 units/mL) and streptomycin $(100 \mu \mathrm{g} / \mathrm{mL})$ under humidified atmosphere of $5 \% \mathrm{CO}_{2}$ in air. Subculture was performed every 3-4 days from subconfluent $(\sim 80 \%)$ cultures using trypsin-EDTA solution.

\section{Ratiometric fluorescence imaging of metal ions in living cells}

HeLa cells $\left(1 \times 10^{5}\right)$ were cultured on $3.5 \mathrm{~cm}$ glass-based dish (Iwaki) for 2 days at $37^{\circ} \mathrm{C}$ in $\mathrm{CO}_{2}$ incubator. The cells were washed with HBS (20 mM HEPES, $107 \mathrm{mM} \mathrm{NaCl}, 6 \mathrm{mM} \mathrm{KCl}, 1.2 \mathrm{mM} \mathrm{MgSO}_{4}$, $2 \mathrm{mM} \mathrm{CaCl}_{2}, 11.5 \mathrm{mM}$ glucose, adjusted to $\mathrm{pH} 7.4$ with $\mathrm{NaOH}$ ) twice and pre-treated with probe 12 $(5 \mu \mathrm{M})$ in $\mathrm{HBS}(+)$ for $20 \mathrm{~min}$ at $37^{\circ} \mathrm{C}$. After washed with HBS $(+)$, the cells were treated with HBS containing pyrithione $(100 \mu \mathrm{M})$ and each metal ion $(5 \mu \mathrm{M})$ for $30 \mathrm{~min}$ at $37^{\circ} \mathrm{C}$ and subjected to fluorescence imaging with confocal microscopy (TCS SP8, Leica Microsystems) equipped with HyD detector $\left(\lambda_{\mathrm{ex}}=488 \mathrm{~nm}\right)$.

\section{Data availability}

The authors declare that all data supporting the findings of this study are available within the article and Supplementary Information files, and from the corresponding author on request.

\section{References}

1. Kim, H. N.; Ren, W. X.; Kim, J. S.; Yoon, J., Fluorescent and colorimetric sensors for detection of lead, cadmium, and mercury ions, Chem. Soc. Rev., 41, 3210-3244 (2012)

2. Rahman, Z.; Singh, V. P., The relative impact of toxic heavy metals (THMs) (arsenic (As), cadmium $(\mathrm{Cd})$, chromium $(\mathrm{Cr})(\mathrm{VI})$, mercury $(\mathrm{Hg})$, and lead $(\mathrm{Pb}))$ on the total environment: an overview, Environ. Monit. Assess., 192:419 (2019).

3. Tchouwou, P. B., Yedjou, C. G.; Patlolla, A. K.; Sutton, D. J., Heavy metal ion toxicities and the 
environment, Molecular, Clinical Environmental Toxicology, 101, 133-164 (2012).

4. Dalmieda, J.; Kruse, P., Metal cation detection in drinking water, Sensors, 19, 5134 (2019).

5. Que, E. L.; Bleher, R.; Duncan, F. E.; Kong, B. Y.; Gleber, S. C.; Vogt, S.; Chen, S.; Garwin, S. A.; Bayer, A. R.; Dravid, V. P.; Woodruff, T. K.; O’Halloran, T. V., Quantitative mapping of zinc fluxes in the mammalian egg reveals the origin of fertilization-induced zinc sparks, Nat. Chem., 7, 130-139 (2015).

6. Dodani, S. C.; Firl, A.; Chan, J.; Nam, C. I.; Aron, A. T.; Onak, C. S.; Ramos-Torres, K. M., Paek, J.; Webster, C. M.; Feller, M. B.; Chang, C. J., Copper is an endogenous modulator of neural circuit spontaneous activity, Proc. Natl. Acad. Sci. USA, 46, 16280-16285 (2014).

7. Egawa, T.; Hanaoka, K.; Koide, Y.; Ujita, S.; Takahashi, N.; Ikegaya, Y.; Matsuki, N.; Terai, T.; Ueno, T.; Komatsu, T.; Nagano, T., Development of a far-red to near-infrared fluorescence probe for calcium ion and its application to multicolor neuronal imaging, J. Am. Chem. Soc., 133, $14157-$ 14159 (2011).

8. Valeur, B.; Leray, I., Design principles of fluorescent molecular sensors for cation recognition, Coord. Chem. Rev., 205, 3-40 (2000).

9. Yeung, M. C.-L., Yam, V. W.-W., Luminescent cation sensors: from host-guest chemistry, supramolecular chemistry to reaction-based mechanism, Chem. Soc. Rev., 44, 4192-4202 (2015).

10. Aron, A. T.; Ramos-Tress, K. M.; Cotruvo, Jr., J. A.; Chang, C. J., Recognition- and reactivitybased fluorescent probes for studying transition metal signaling in living systems, Acc. Chem. Res., 48, 2434-2442 (2015).

11. Escudero, D., Revising intramolecular photoinduced electron transfer (PET) from first-principles, Acc. Chem. Res., 49, 1816-1824 (2016).

12. Li, Y.; Zhong, H.; Huang, Y.; Zhao, R., Recent advances in AIEgens for metal ion biosensing and bioimaging, Molecules, 24, 4593 (2019).

13. Lake, R. J.; Yang, Z.; Zhang, J.; Lu, Y., DNAzymes as activity-based sensors for metal ions: recent applications, demonstrated advantages, current challenges, and future directions, Acc. Chem., Res., 52, 3275-3286 (2019).

14. Bourassa, D.; Elitt, C. M.; McCallum, A. M.; Sumalekshmy, S.; McRae, R. L.; Morgan, M. T.; Siegel, N.; Perry, J. W.; Rosenberg, P. A.; Fahrni, C. J., Chromis-1, A ratiometric fluorescent probe optimized for two-photon microscopy reveals dynamic changes in labile $\mathrm{Zn}$ (II) in differentiating oligodendrocytes, ACS Sensors, 3, 458-467 (2018).

15. Park, S.-H.; Kwon, N.; Lee, J.-H.; Yoon, J.; Shin, I., Synthetic ratiometric fluorescent probes for detection of ions, Chem. Soc. Rev., 49, 143-179 (2020).

16. Grynkiewicz, G.; Poenie, M.; Tsien, R. Y., A new generation of $\mathrm{Ca}^{2+}$ indicators with greatly improved fluorescence properties, J. Biol. Chem., 260, 3440-3450 (1985).

17. Takashima, I.; Kinoshta, M.; Kawagoe, R.; Nakagawa, S.; Sugimoto, M.; Hamachi, I.; Ojida, A., 
Design of ratiometric fluorescent probes based on arene-metal-ion interactions and their application to CdII and hydrogen sulfide imaging in living cells, Chem., Euro., J., 20, 2184-2192 (2014).

18. Lee, H, N.; Kim, H. N., Swamy, K. M. K.; Park, M. S., Kim, J.; Lee, H.; Lee, K.-H.; Park, S.; Yoon, J., New acridine derivatives bearing immobilized azacrown or azathiacrown ligand as fluorescent chemosensors for $\mathrm{Hg}^{2+}$ and $\mathrm{Cd}^{2+}$, Tetrahedron Lett., 49, 1261-1265 (2008).

19. Fages, F.; Desvergne, J.-P.; Bouas-Laurent, H.; Marsau, P.; Lehn, J.-M.; Kotzyba-Hibert, F.; Albrecht-Gary, A.-M.; Al-Joubbeh, M., Anthraceno-cryptands: A new class of cation-complexing macrocycle fluorophores, J. Am. Chem. Soc., 111, 8672-8680 (1989).

20. Nugent, J. W.; Reibenspies, J. H.; Hancock, R. D., Controlling the fluorescence response of PET sensors via the metal-ion $\pi$-contacting ability of the fluorophore: coumarin, a weaker $\pi$-contacter, Inorg. Chem., 54, 9976-9988 (2015).

21. Bondi, A., van der Waals Volumes and Raddi, J. Phys. Chem., 1964, 68, 441-451.

22. Takashima, I.; Kanegae, A.; Sugimoto, M.; Ojida, A., Aza-crown-ether-appended xanthene: selective ratiometric fluorescent probe for silver (I) ion based on arene-metal ion interaction, Inorg. Chem., 53, 7080-7082 (2014).

23. Smith, D. G.; Topolmicki, I. L.; Zwicker, V. E.; Jolliffe, K. A.; New, E. J., Fluorescent sensing arrays for cations and anions, Analyst, 142, 3549-3563 (2017).

24. Sarkar, T.; Selvakumar, K.; Motiei, L.; Margulies, Message in a molecule, Nat. Commun., 7:11374 (2016).

25. Yuen, L. H.; Franzini, R. M.; Tan, S. S.; Kool, E. T., Large-scale detection of metals with a small set of fluorescent DNA-like chemosensors, J. Am. Chem. Soc., 136, 14576-14582 (2014).

26. Palacios, M. A.; Wang, Z.; Montes, V. A.; Zyryanov, G. V.; Anzenbacher Jr., P., Rational Design of a minimal size sensor array for metal ion detection, J. Am. Chem. Soc., 130, 10307-10314 (2008).

27. Huston, M. E.; Engleman, C.; Czarnik, A. W., Chelatoselective fluorescence perturbation in anthrylazamacrocycle conjugate probes. Electrophilic aromatic cadmiation, J. Am. Chem., Soc., 112, 7054-7056 (1990).

28. Colenda, B. E.; Lee, H.-S.; Reibenspies, J. H.; Hancock, R. D., Indole-based fluorescence sensors for both cations and anions, Inorg. Chim. Acta., 482, 478-490 (2018).

29. Nugent, J. W.; Lee, H.; Lee, H.-S.; Reibenspies, J. H.; Hancock, R. D., The effect of $\square$ contacts between metal ions and fluorophores on the fluorescent PET sensors: Implications for sensor design for cations and anions, Inorg. Chem., 53, 9014-9026 (2014).

30. Lenthall, J. T.; Steed, J. W., Organometallic cavitands: Cation-p interactions and anion binding via $\pi$-metallation, Coord. Chem. Rev., 251, 1747-1760 (2007).

31. Nugent, J. W.; Lee, H.; Lee, H.-S.; Reibenspies, J. H.; Hancock, R. D., Mechanism of chelation enhanced fluorescence in complexes of cadmium (II), and a possible new type of anion sensor, Chem. Commun., 49, 9749-9751 (2013). 
517 32. Hitomi, Y.; Nagai, T.; Kodera M., A silver complex with an N, S, S-macrocyclic ligand bearing an 518 anthracene pendant arm for optical ethylene monitoring, Chem. Commun., 48, 10392-10394 $519 \quad$ (2012).

\section{Acknowledgements}

523 This work was supported by the Grant-in-Aid for Scientific Research on Innovative Areas "Chemistry 524 for Multimolecular Crowding Biosystems" (JSPS KAKENHI Grant No. JP17H06349) and the Grant525 in-Aid for Scientific Research B (JSPS KAKENHI grant no. JP20H02861 to A. O.). A.O. acknowl526 edges Naito Science Foundation and Toray Science Foundation for their financial supports. S.U. 527 acknowledges Grant-in-Aid for Young Scientists B (JSPS KAKENHI Grant No. JP17K14518) for its 528 financial support.

\section{Author contributions}

532 A.O. designed the experiments. A.K., Y.T., I.T., S.U., and R.K. performed the experiments. U.K. and 533 M.S. performed the computational theoretical analyses. A.O., J.W., and M.S. analyzed and discussed 534 the data. The manuscript was written by A.O., J.W., and M.S.

\section{Competing interests}

538 The authors declare no competing interests.

\section{$541 \quad$ Additional information}

542 Supplementary information is available for this paper at 
Figures

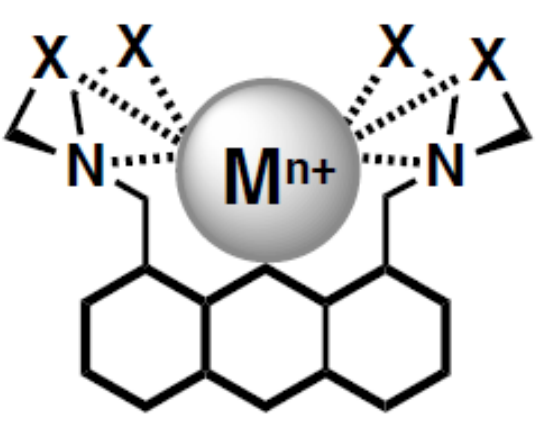

Type I

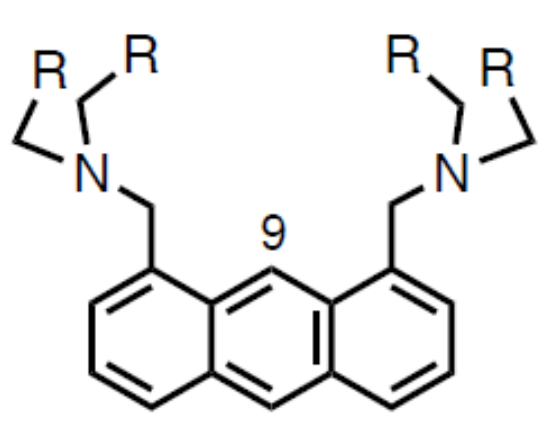

1: $R=2$-pyridy

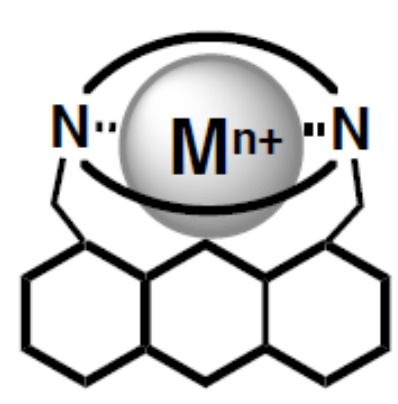

Type II

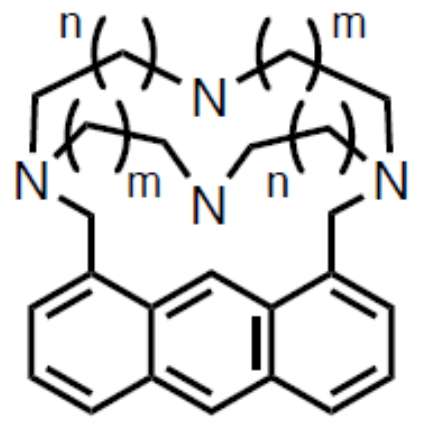

2: $n=1, m=1$
3: $n=1, m=2$
4: $n=2, m=2$

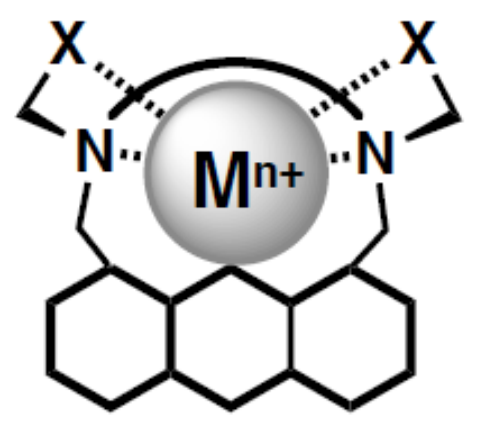

Type III

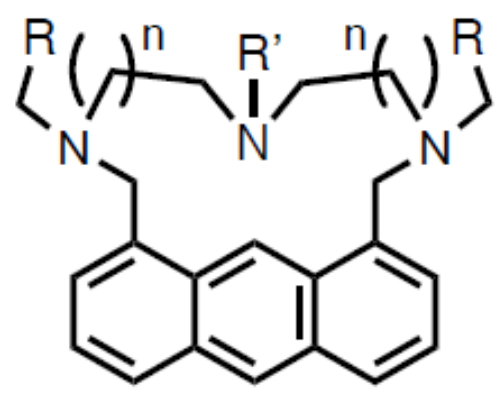

5: $n=1, R=2-p y r i d y l, ~ R '=H$ 6: $n=2, R=2$-pyridyl, $R^{\prime}=H$ 7: $n=1, R, R^{\prime}=2$-pyridyl

Figure 1

General designs (upper) and molecular structures (lower) of tricyclic fluorescent probes for metal ion sensing based on arene-metal-ion contact (AM-contact). 
a

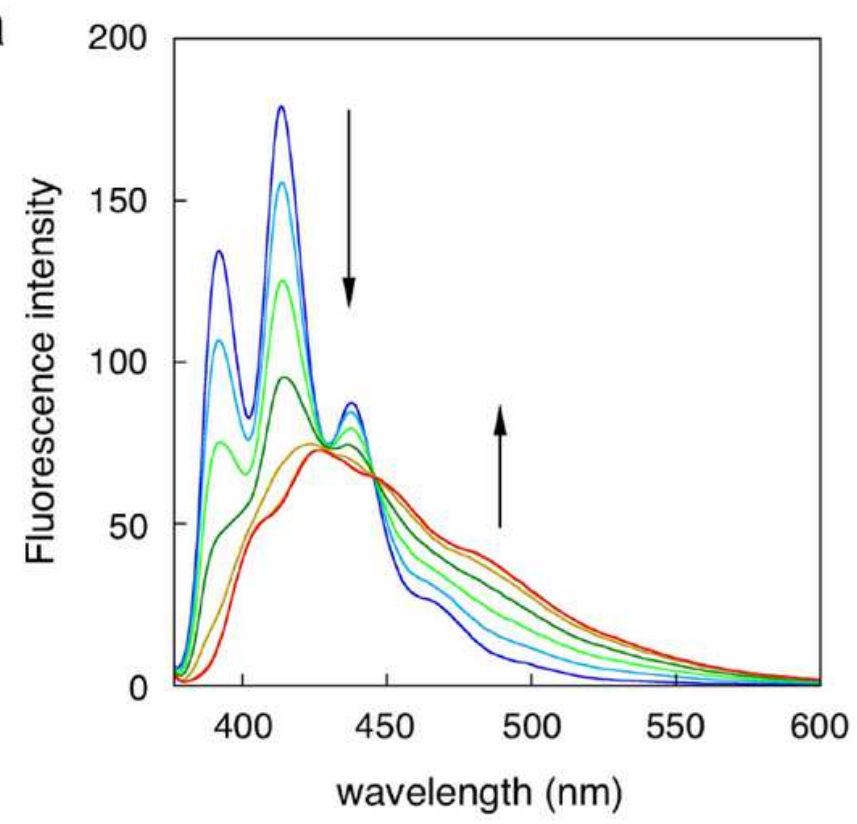

C

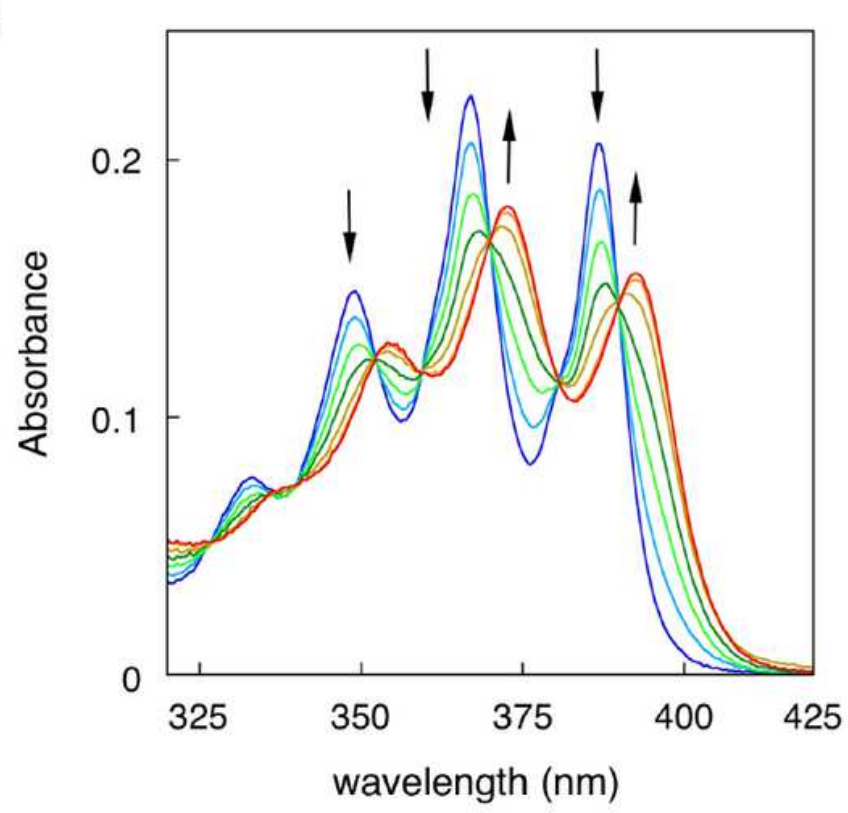

b

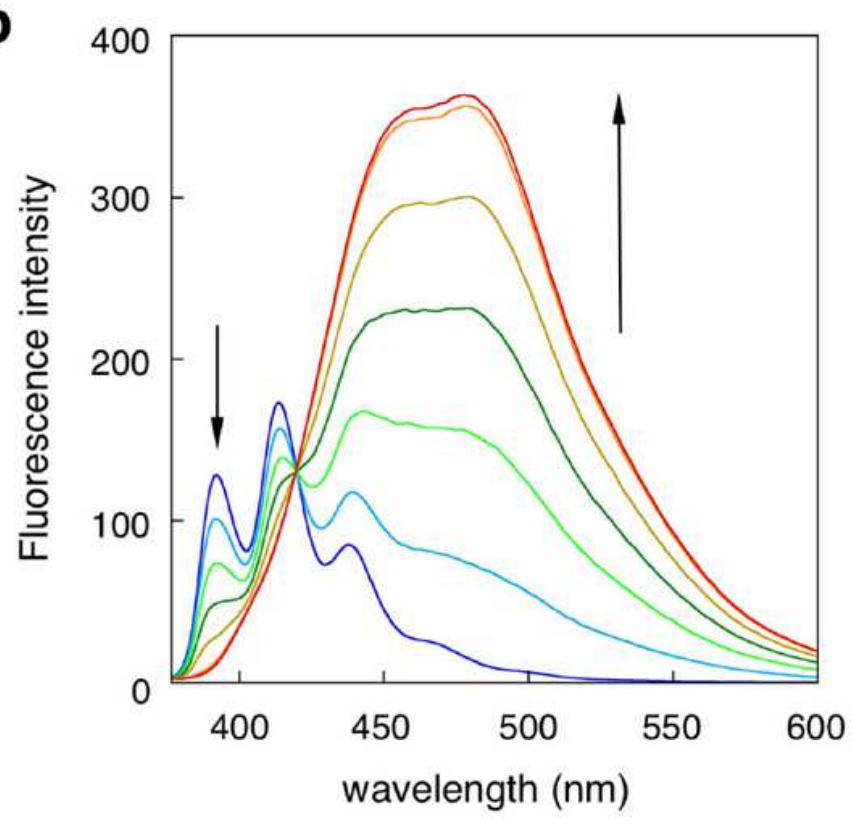

d

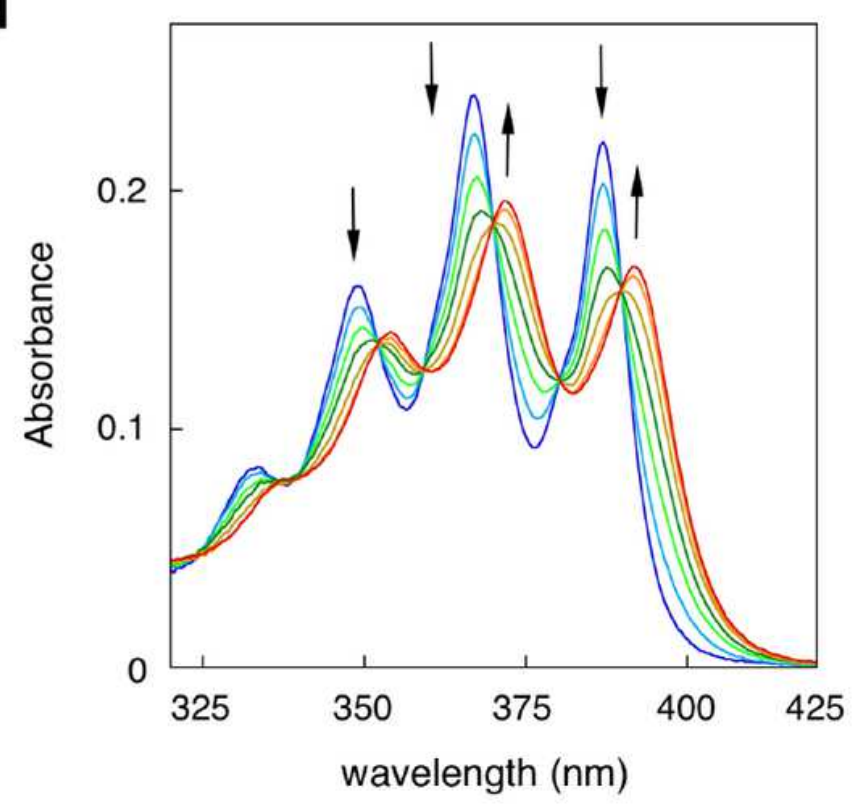

Figure 2

Fluorescence and absorption spectral changes of probe 5 upon addition of $\mathrm{ZnCl} 2$ (a and c) or $\mathrm{CdCl} 2$ (b and d). Measurement conditions: [5] $=25 \mu \mathrm{M}$, [ZnCl2 or $\mathrm{CdCl} 2]=0-30 \mu \mathrm{M}, 50 \mathrm{mM} \mathrm{HEPES}(\mathrm{pH} 7.4) / \mathrm{MeOH}$ $=1: 1$, lex $=365 \mathrm{~nm}, 25^{\circ} \mathrm{C}$. 

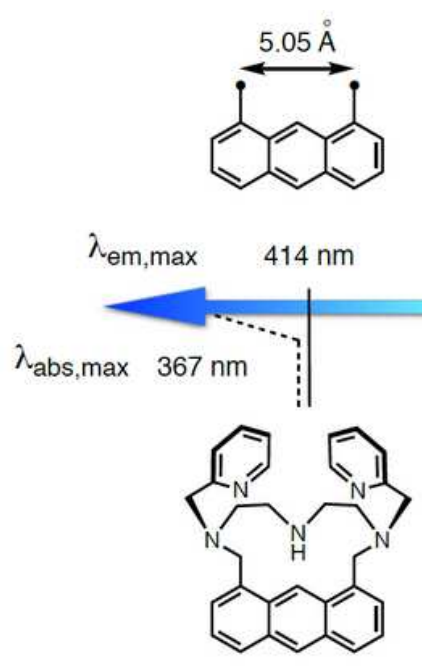

5

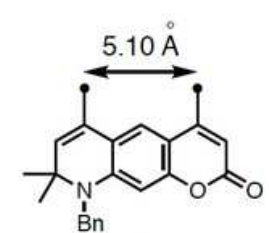

$490 \mathrm{~nm}$

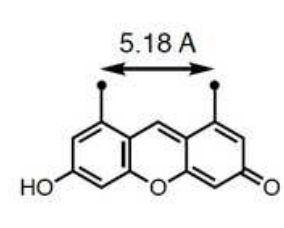

$528 \mathrm{~nm}$

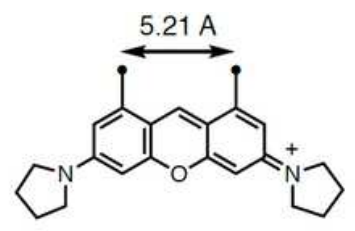

$591 \mathrm{~nm}$

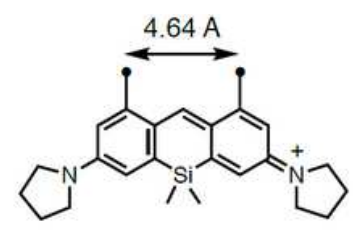

$687 \mathrm{~nm}$

\section{Figure 3}

Structures and fluorescence spectroscopic properties of tricyclic fluorophore probes bearing a BPTN ligand.

a
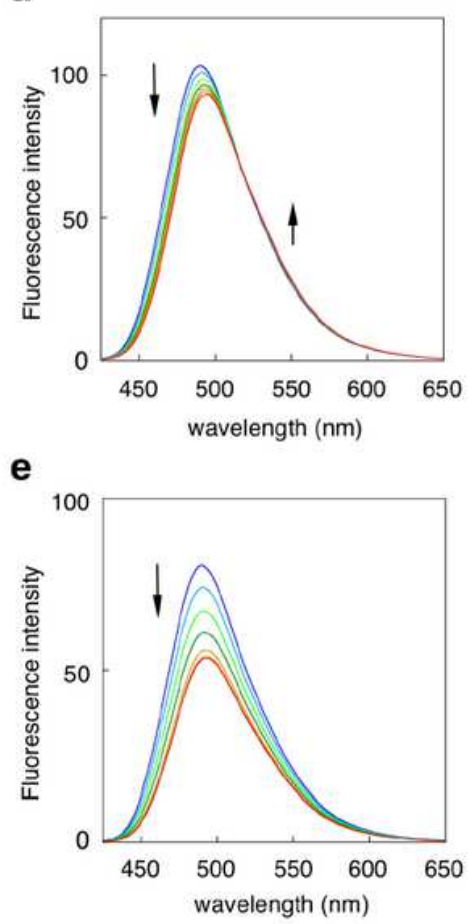

b

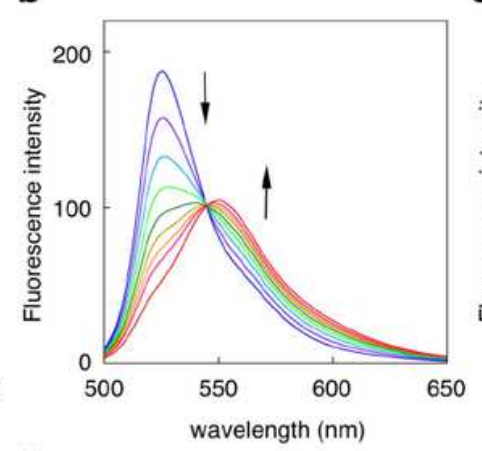

f

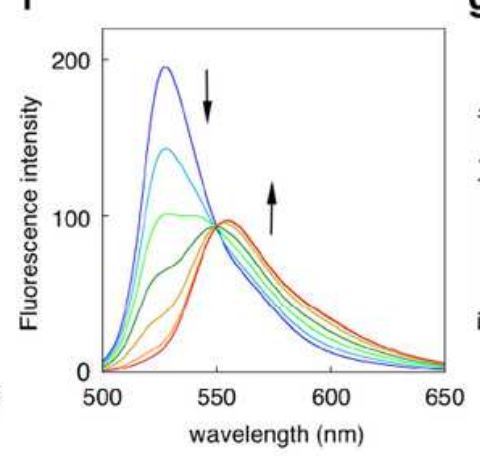

c

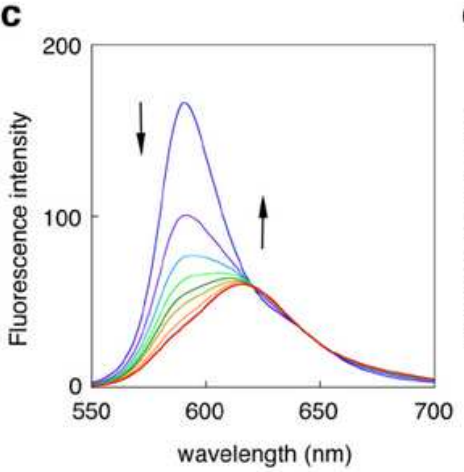

g

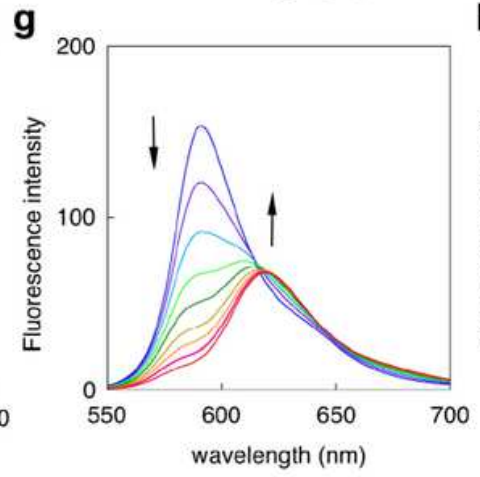

d

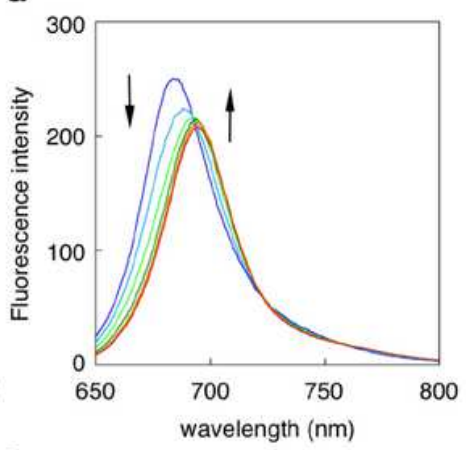

h

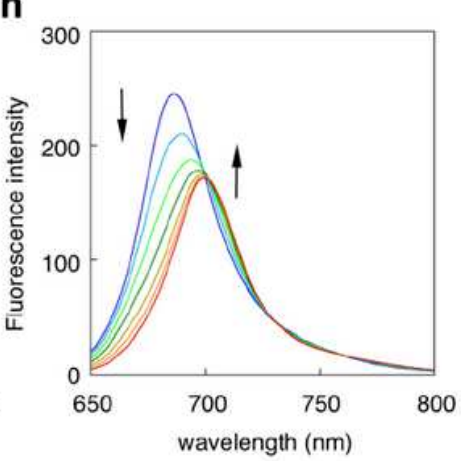

\section{Figure 4}

Fluorescence spectral changes of probes 8-11 (from left to right) upon addition of $\mathrm{ZnCl} 2(\mathrm{a}-\mathrm{d}$ ) or $\mathrm{CdCl} 2$ $(\mathrm{e}-\mathrm{h})$. Measurement conditions: [probe] $=5 \mu \mathrm{M}(9,10,11)$ or $10 \mu \mathrm{M}(8), 50 \mathrm{mM} \mathrm{HEPES}(\mathrm{pH} 7.4) / \mathrm{MeOH}=$ $1: 1,25^{\circ} \mathrm{C}$. 


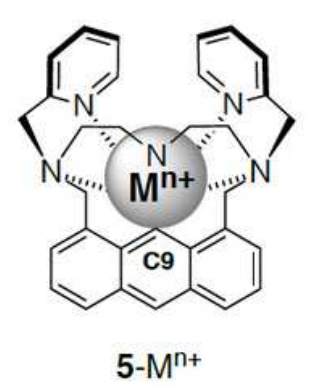

C

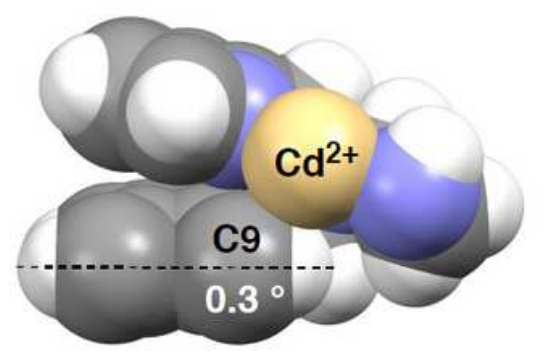

a

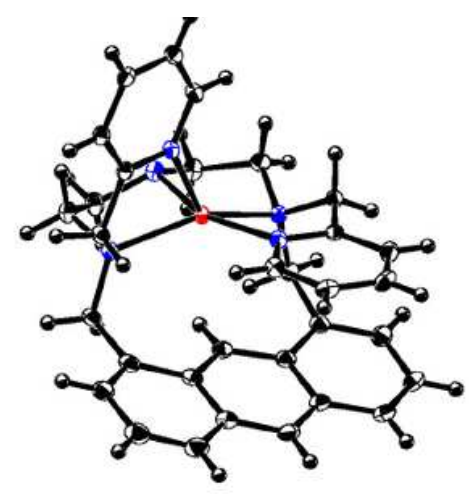

d

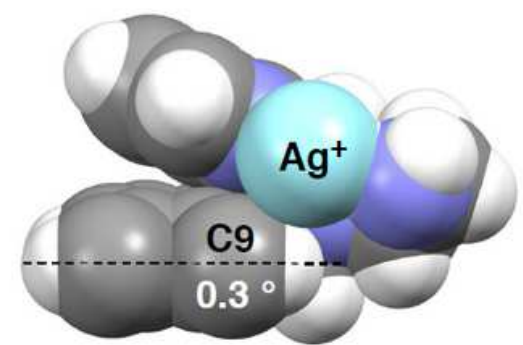

b

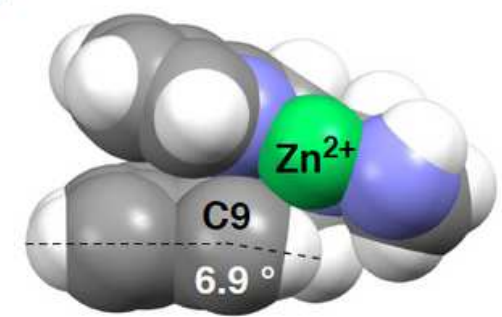

e

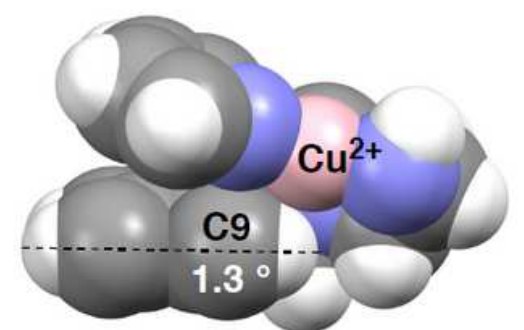

\section{Figure 5}

X-ray structures of the metal ion complexes $5-\mathrm{Mn}+(\mathrm{Mn}+=\mathrm{Zn} 2+, \mathrm{Cd} 2+, \mathrm{Ag}+$, or Cu2 +$)$. (a) ORTEP diagram ( $50 \%$ probability ellipsoids) of $5-\mathrm{Zn} 2+(\mathrm{C} 32 \mathrm{H} 32 \mathrm{~N} 408 \mathrm{Cl} 2 \mathrm{Zn})$. The perchlorate anions are omitted for clarity. (b-e) Cross-sectional views of the metal ion complexes of 5. 
a

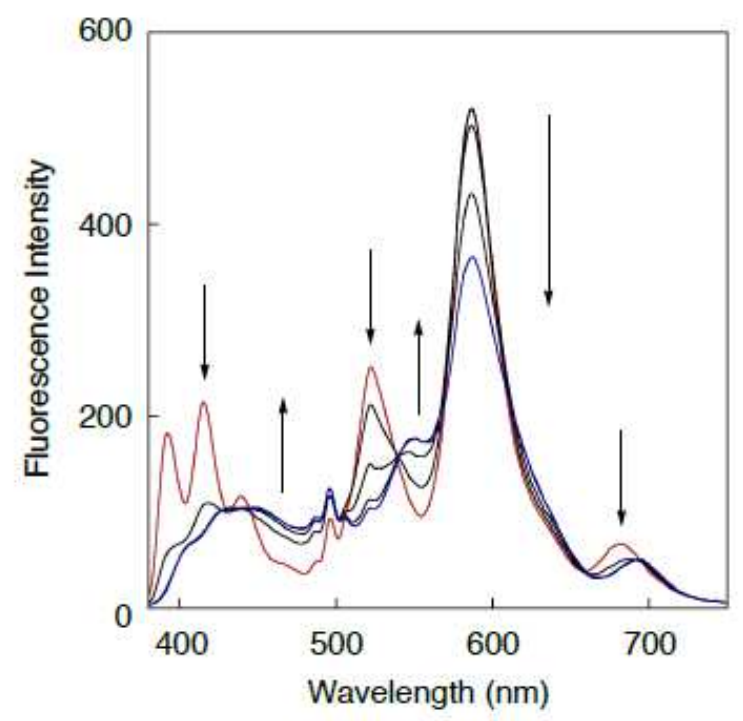

b

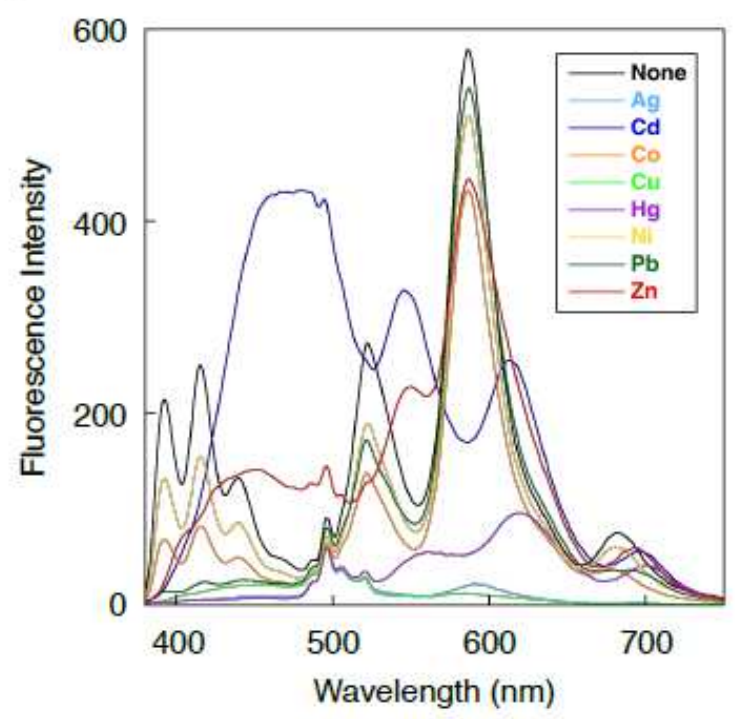

C

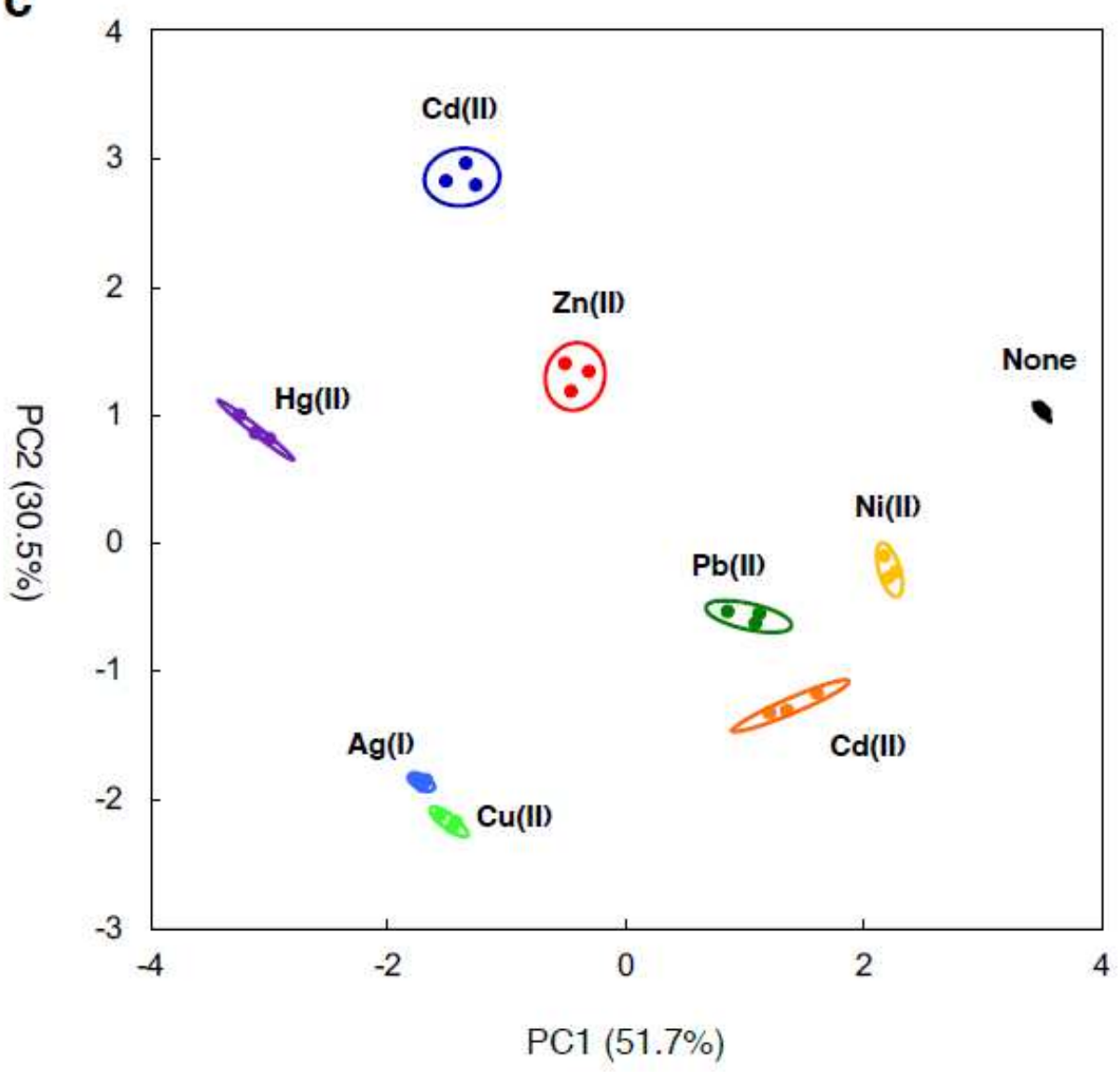

Figure 6

Multicolor fluorescence sensing of metal ions. (a) Fluorescence spectral change of the set of probes 5, 9, 10 , and 11 upon addition of $\mathrm{ZnCl} 2(0-30 \mu \mathrm{M})$. (b) Fluorescence spectral change of the set of probes upon addition of various metal ions $(30 \mu \mathrm{M})$. (c) PCA plot of the two principle components (PC1 and PC2) for eight metal ions $(30 \mu \mathrm{M})$. Measurement conditions: $[5,9,10]=2 \mu \mathrm{M},[11]=4 \mu \mathrm{M}, 50 \mathrm{mM}$ HEPES $(\mathrm{pH}$ 7.4) $/ \mathrm{MeOH}=1: 1,25^{\circ} \mathrm{C}$. lex $=254 \mathrm{~nm}$. 
a

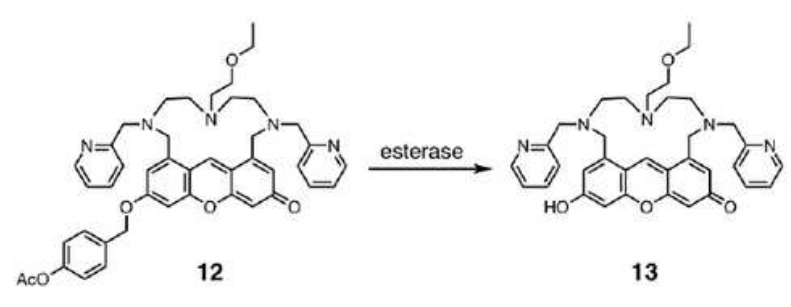

b

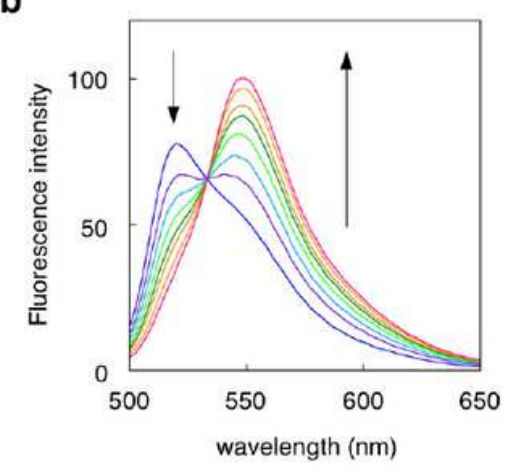

c

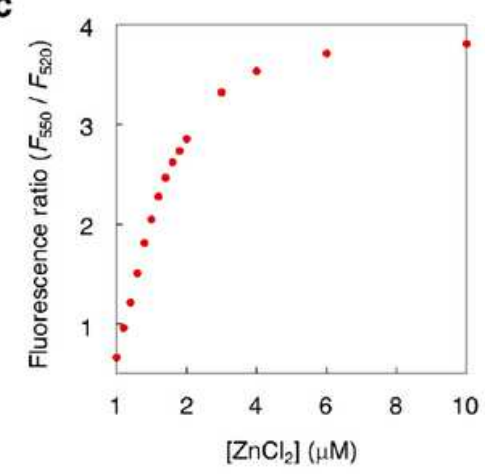

d

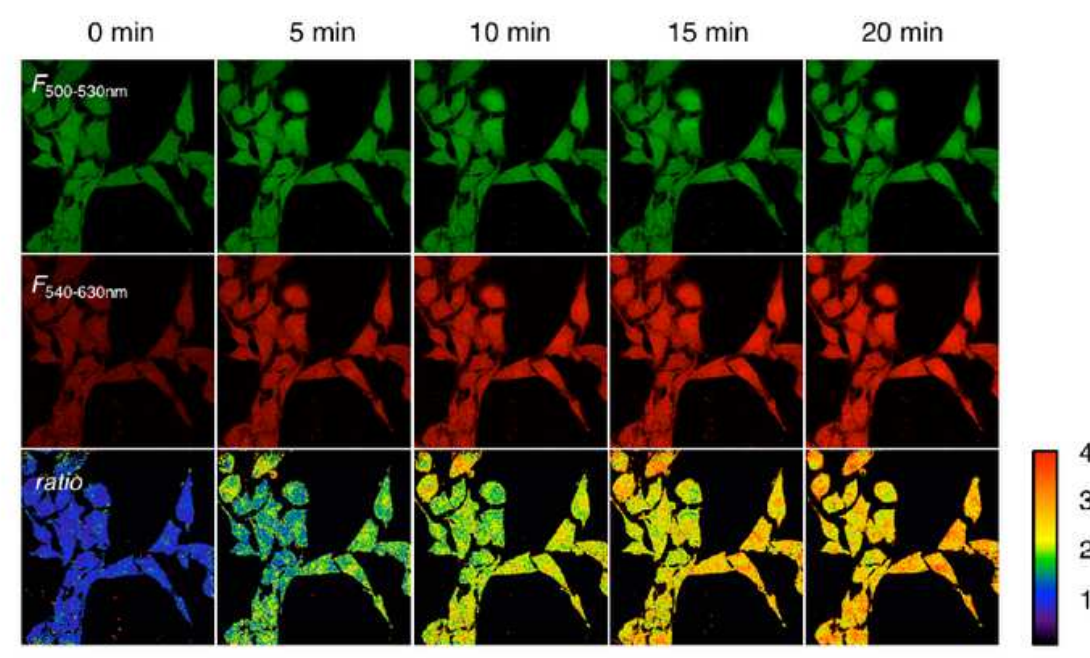

e

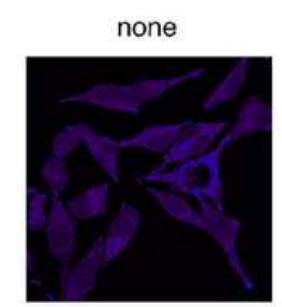

Cd(II)

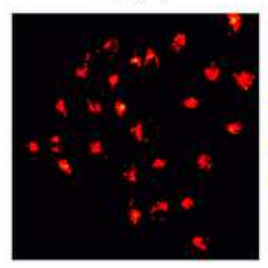

$\mathrm{Cu}$ (II)

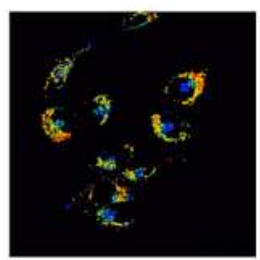

$\mathrm{Hg}$ (II)

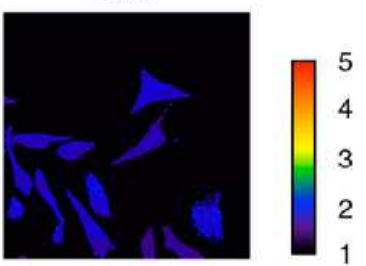

\section{Figure 7}

Ratiometric fluorescence detection of metal ions in living cells. (a) Structures of probe 12 and its hydrolyzed product 13. (b) Fluorescence spectral change of 13 upon addition of $\mathrm{ZnCl} 2$. Measurement conditions: [13] $=1 \mu \mathrm{M}$, [ZnCl2] $=0,0.2,0.4,0.6,0.8,1.0,1.4,2 \mu \mathrm{M}, 50 \mathrm{mM}$ HEPES $100 \mathrm{mM} \mathrm{NaCl}, \mathrm{pH} 7.4$, $25{ }^{\circ} \mathrm{C}$, lex $=488 \mathrm{~nm}$. (c) Plot of the fluorescence intensity ratio (F550nm / F520 nm) of 13 upon addition of $\mathrm{ZnCl2}$. (d) Time-lapse images of $\mathrm{Zn}(\mathrm{II})$ inside HeLa cells. The cells were incubated with probe 12 (5 $\mu \mathrm{M})$ followed by the treatment with $\mathrm{ZnCl} 2(5 \mu \mathrm{M})$ in the presence of pyrithione $(100 \mu \mathrm{M})$. The ratio images were obtained from the imaging data acquired at two detection channels (F540-630 nm and F500-530 nm). (e) Ratiometric detection of various metal ions in HeLa cells. The fluorescence images were acquired at 5 min after the treatment of the cells with each metal ion $(5 \mu \mathrm{M})$ in the presence of pyrithione $(100 \mu \mathrm{M})$.

\section{Supplementary Files}

This is a list of supplementary files associated with this preprint. Click to download.

- SupplementaryInfoCommunChem.pdf 